Supporting Information

\title{
Organic Laser Molecule with High Mobility, High Photoluminescence Quantum Yield, and Deep-Blue Lasing Characteristics
}

Dan Liu, ${ }^{\mathrm{a}, \mathrm{c}}$ Jianbo De, ${ }^{\mathrm{d}}$ Haikuo Gao, ${ }^{\mathrm{a}, \mathrm{c}}$ Suqian Ma, ${ }^{\mathrm{e}}$ Qi Ou, ${ }^{\mathrm{f}}$ Shuai Li, ${ }^{\mathrm{d}}$ Zhengsheng Qin, ${ }^{\mathrm{a}, \mathrm{c}}$ Huanli Dong, ${ }^{\mathrm{a}, c^{*}}$ Qing Liao, ${ }^{\mathrm{d}}$ Bin Xu, ${ }^{\mathrm{e}}$ Qian Peng, ${ }^{\mathrm{a}}$ Zhigang Shuai, ${ }^{\mathrm{f}}$ Wenjing Tian, ${ }^{\mathrm{e}}$ Hongbing Fu, ${ }^{\mathrm{d}}$ Xiaotao Zhang, ${ }^{\mathrm{b}}$ Yonggang Zhen, ${ }^{\mathrm{a}}$ and Wenping $\mathrm{Hu}^{\mathrm{b}}$

${ }^{a}$ Beijing National Laboratory for Molecular Science, Key Laboratory of Organic Solids, Institute of Chemistry, Chinese Academy of Sciences, Beijing 100190, China

${ }^{\mathrm{b}}$ Tianjin Key Laboratory of Molecular Optoelectronic Sciences, Department of Chemistry, School of Science, Tianjin University and Collaborative Innovation Center of Chemical Science and Engineering, Tianjin 300072, China

${ }^{c}$ University of Chinese Academy of Sciences, Beijing 100049, China

${ }^{\mathrm{d} B e i j i n g ~ K e y ~ L a b o r a t o r y ~ f o r ~ O p t i c a l ~ M a t e r i a l s ~ a n d ~ P h o t o n i c ~ D e v i c e s, ~ D e p a r t m e n t ~ o f ~ C h e m i s t r y, ~ C a p i t a l ~}$ Normal University, Beijing, 100048, China

${ }^{\mathrm{e}}$ State Key Laboratory of Supramolecular Structure and Materials, Jilin University, Changchun 130012, China

${ }^{\mathrm{f}}$ Department of Chemistry, Tsinghua University, Beijing 100084, China 


\section{Content list}

Scheme S1 Synthesis route of LD-1

Figure S1 Optical and fluorescence images of LD-1 powder and solution

Figure S2 Cyclic Voltammogram of LD-1 in acetonitrile solution

Figure S3 Thermal gravimetric analysis of LD-1

Figure S4 Structural and intermolecular interactions of LD-1 crystal

Figure S5 Optical images of LD-1 crystals and its Size distribution chart

Figure S6 Atomic force microscopy of an individual LD-1 crystal

Figure S7 A unit cell of LD-1 crystal and molecular packing arrangement with (010) plane

Figure S8 ASE properties of LD-1 crystal

Figure S9 Loss coefficient of LD-1 crystal

Figure S10 Theoretically calculated and experiment absorption and emission spectra

Figure S11 PL spectra of LD-1 crystal under different pump densities

Figure S12 PL spectra and peak-separation-fitting spectra of LD-1 crystal

Figure S13 Schematic of LD-based transistor with bottom-gate top-contact device geometry

Figure S14 Typical transfer and output curves of LD-1 based OFET

Figure S15 A summary of high-performance blue materials with lasing and mobility

Figure S16 The CCD images of LD-1 OLET device captured under off-state and on-state

Figure S17 The electroluminescence spectra of LD-based OLETs at different $\mathrm{V}_{\mathrm{GS}}$

Figure S18 PL spectrum of vacuum-deposited LD-1 thin film

Figure S19 $\quad{ }^{1} \mathrm{H}$ NMR spectrum of LD-1 in deuterated chloroform

Figure S20 $\quad{ }^{13} \mathrm{C}$ NMR spectrum of LD-1 in deuterated chloroform

Figure S21 High resolution mass spectrometry of LD-1

Table S1 A summary of materials for both mobility and laser property

Table S2 A summary of device performances for currently reported fluorene derivatives

Table S3 Crystal Data and Structure Refinement for LD-1

Table S4 Time-resolved PL measurements of LD-1 in solution and single crystals

Table S5 Theoretical and experimental rate constants and PLQY

Table S6 A summary of quality factor $(\mathrm{Q})$ for currently reported literatures

Reference 


\section{Experimental section}

\section{Materials and instruments:}

2,7-Dibromofluorene (1), phenylboronic acid (2) and $\mathrm{Pd}\left(\mathrm{PPh}_{3}\right)_{4}$ was purchased from J\&K Chemical Co., in addition, all solvents and materials were used directly without further purification. ${ }^{1} \mathrm{H}$ NMR spectra were recorded on a Bruker $400 \mathrm{MHz}$ spectrometer as solution in deuterochloroform $\left(\mathrm{CDCl}_{3}\right)$, chemical shifts were reported as $\delta$ values $(\mathrm{ppm})$ relative to the tetramethylsilane using the residual solvent signal $\left(\mathrm{CDCl}_{3}\right.$ 7.26, and TMS 0.00) as internal standard. Proton $\left({ }^{1} \mathrm{H}\right)$ NMR information is given in the following format: multiplicity (s, singlet; $\mathrm{d}$, doublet; t, triplet), coupling constant (s) $(\mathrm{J})$ in Hertz (Hz), number of protons. ${ }^{13} \mathrm{C}$ NMR spectra is obtained on a Bruker neo $600 \mathrm{MHz}$ spectrometer in ppm relative to residual $\mathrm{CDCl}_{3}$ (77). High resolution mass spectrometry were obtained at the Analytical Center of the Institute of Chemistry, Chinese Academy of Science (ICCAS). UV-vis absorption spectra of solution and crystals were recorded by a Jasco V-570 spectrometer and an Analytik Jena Specord 210 spectrophotometer equipped with an integrating sphere, respectively. Photoluminescence spectra of solution was recorded on a Jasco FP-6600 spectrophotometer. Absolute Photoluminescence quantum yield (PLQY) measurement (LabSphere $®$, FluoroMax-4, HORIBA JobinYvon, PLQY software package) was used for crystalline and solution sample by using the integrating sphere. Time-resolved peak fluorescence of LD-1 in $\mathrm{CH}_{2} \mathrm{Cl}_{2}$ solution and crystals were recorded by FSL 980. Thermal gravimetric analysis (TGA) was performed on a STA 409 PC thermogravimeter at a heating rate of $10{ }^{\circ} \mathrm{C} \mathrm{min}^{-1}$ under nitrogen atmosphere. Electrochemical measurements was performed with a CHI660C electrochemistry station. UPS measurements were recorded on a KRATOS Axis Ultra DLD spectrometer.

Single crystals of LD-1 were obtained from the saturated $\mathrm{CH}_{2} \mathrm{Cl}_{2}$ : ethanol = $1: 2$ at room temperature and its XRD data was collected on a Rigaku Saturn 724 CCD diffract meter with graphite monochromated Mo Ka radiation. The CCDC numbers for LD-1 is 1942276 and the crystallographic data are given in Table S3. AFM images were obtained by using a Digital Instruments Nanoscope III atomic force microscope in tapping mode.

The electronic structure calculation for the solution scenario is carried out with time-dependent density functional theory (TD-DFT) in Gaussian $16^{[1]}$ quantum chemistry package. 6-31G (d) basis set and M06-2X functional ${ }^{[2]}$ are applied to all calculations, together with a ONIOM $(\mathrm{QM}: \mathrm{MM}){ }^{[3]}$ to depict the solvent effect. The optical properties are also theoretically investigated with MOMAP 2.1.0 $0^{[4]}$ software.

\section{Synthetic details:}

2,7-diphenyl-9H-fluorene (LD-1): The synthesis of LD-1 is according the literature. ${ }^{[5]}$ 2,7-Dibromofluorene (1 g, $3 \mathrm{mmol}$ ) of 1, phenylboronic acid (1.463 g, $12 \mathrm{mmol})$ of 2, $\mathrm{Pd}\left(\mathrm{PPh}_{3}\right)_{4}$ (208 $\mathrm{mg}, 6 \mathrm{~mol} \%$ ) were combined, then protected under argon, toluene $(30 \mathrm{~mL}), \mathrm{K}_{2} \mathrm{CO}_{3}$ solution $(6 \mathrm{~mL}, 2 \mathrm{M})$ was slowly added dropwise via syringe. the reaction mixture was heated to $100{ }^{\circ} \mathrm{C}$ for 3 days. After cooling to room temperature, the resulting mixture was extracted with chloroform $(3 \times 75 \mathrm{~mL})$, The combined organic phases were dried over $\mathrm{MgSO}_{4}$, The solvent was removed under reduced pressure to give a residue, which was purified by flash column chromatography over silica gel eluting with PE/DCM (10:1 v/v) to obtain LD-1 (0.6 g, $63 \%)$ as a white powder. And ${ }^{1} \mathrm{H}$ NMR spectrum, ${ }^{13} \mathrm{C}$ NMR spectrum of LD-1 in deuterated chloroform are 
shown in Figure S19 and Figure S20, high resolution mass spectrometry of LD-1 is displayed in Figure S21. ${ }^{1} \mathrm{H}$ NMR $\left(\mathrm{CDCl}_{3}\right): \delta=4.03(\mathrm{~s}, 2 \mathrm{H}), 7.36(\mathrm{t}, \mathrm{J}=7.36 \mathrm{~Hz}, 2 \mathrm{H}), 7.47(\mathrm{t}, \mathrm{J}=7.36 \mathrm{~Hz}$, $4 \mathrm{H}), 7.66(\mathrm{t}, \mathrm{J}=8.46 \mathrm{~Hz}, 6 \mathrm{H}), 7.8(\mathrm{~s}, 2 \mathrm{H}), 7.87(\mathrm{~d}, \mathrm{~J}=7.86 \mathrm{~Hz}, 2 \mathrm{H}) .{ }^{13} \mathrm{C} \mathrm{NMR}\left(600 \mathrm{MHz}, \mathrm{CDCl}_{3}\right)$ : ठ 144.1, 141.5, 140.6, 139.9, 128.8, 127.2, 127.1, 126.1, 123.8, 120.2, 37.1; HRMS: m/z: 319 $\left(\mathrm{M}^{+}\right)$. Anal. calcd for $\mathrm{C}_{25} \mathrm{H}_{28}(\%)$ : C: 94.30 , H: 5.70. Found: C: $94 \%$, H: $5.63 \%$.

\section{Device fabrications and measurements}

ASE measurement: ASE measurement was carried out by a Nd:YAG laser $(355 \mathrm{~nm}, 10 \mathrm{~Hz}, 10$ ns). And the energy of the pumping laser was adjusted by using the calibrated neutral density filters. The beam was focused into a stripe by using a cylindrical lens and a slit. The PL spectra were detected by optical fiber. The peak intensity increases exponentially along with increasing pump stripe length according to the following formula:

$$
I(\lambda)=\frac{A(\lambda) P_{0}}{g(\lambda)}\left(e^{g(\lambda) l}-1\right)
$$

Where $A$ is a parameter proportional to the Photoluminescence quantum yield, $P_{0}$ is the pump intensity, $g$ is the net gain coefficient, $l$ is the pump stripe length. The loss experiment was collected by keeping the length of the pump stripe constant, and moving the pump stripe away from the tip of the LD-1 crystal. Since the output intensity from the end of the stripe $\left(I_{0}\right)$ was constant, the emission was decreased from the tip of the crystal as following equation:

$$
I=I_{0} \mathrm{e}^{-\alpha \mathrm{x}}
$$

Where $x$ is the length between the end of the stripe and the edge of the crystal, and $\alpha$ is the loss coefficient.

OSSL measurements: Selecting wavelength of $355 \mathrm{~nm}, 100 \mathrm{fs}$ pulse width, frequency of $1 \mathrm{KHz}$ femtosecond laser light source to excite the middle position of LD-1 crystals on the 2D sample table (spot diameter of $1 \mathrm{um}$ ). Spatially resolved PL spectra of the selected LD-1 crystals were collected underneath by using a 3D movable objective coupled to an optical fiber. Among them, the change of the excitation point energy is completed by the attenuation.

OFET and OLET device fabrication: High-quality Single crystals for OFETs were prepared by physical vapor transport (PVT). The powder of LD-1 was heated to $130{ }^{\circ} \mathrm{C}$ for 3 hours in argon atmosphere of $10 \mathrm{pa}$, then the crystals were deposited on the OTS-modified $\mathrm{Si} / \mathrm{SiO}_{2}$ substrate. The bottom-gate, top-contact device configuration was fabricated by a "glue the gold film" technique, then, the OFET characteristics were recorded by a Keithley 4200 SCS and Micromanipulator 6150 probe station. Vertical light-emitting transistors (VOLETs) based on LD-1 are also fabricated (Figure S16), whose structures are as follows: ${ }^{\mathrm{n}++} \mathrm{Si} / \mathrm{SiO}_{2} /$ graphene (gate)/ $200 \mathrm{~nm} \mathrm{NPB} / 30 \mathrm{~nm}$ LD-1/ $40 \mathrm{~nm} \mathrm{TmPypB} / 0.5 \mathrm{~nm} \mathrm{LiF} / 1 \mathrm{~nm} \mathrm{Al} / 38.5 \mathrm{~nm} \mathrm{Ag}$. In addition, another device structure comprising of ${ }^{\mathrm{n++}} \mathrm{Si} / \mathrm{SiO}_{2} /$ graphene (gate)/ $200 \mathrm{~nm} \mathrm{NPB/30} \mathrm{nm} \mathrm{LD-1/40} \mathrm{nm} \mathrm{TPBi/0.5} \mathrm{nm} \mathrm{LiF/1}$ $\mathrm{nm} \mathrm{Al} / 38.5 \mathrm{~nm} \mathrm{Ag}$ was also constructed for comparison. And the electrical characteristics were measured also using Keithley 4200 SCS with a Nikon digital camera attached to an optical microscope. Nest, the light emission spectra were obtained by a cryogenically-cooled CCD spectrometer (Princeton) under the inert atmosphere. 


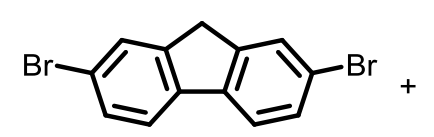

1

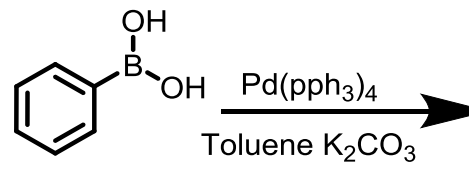

2

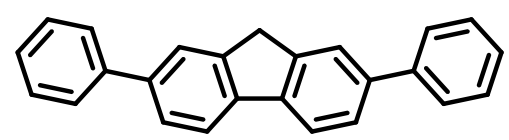

LD-1

Scheme S1. Synthetic route of 2,7-diphenyl-9H-fluorene (LD-1) compound.
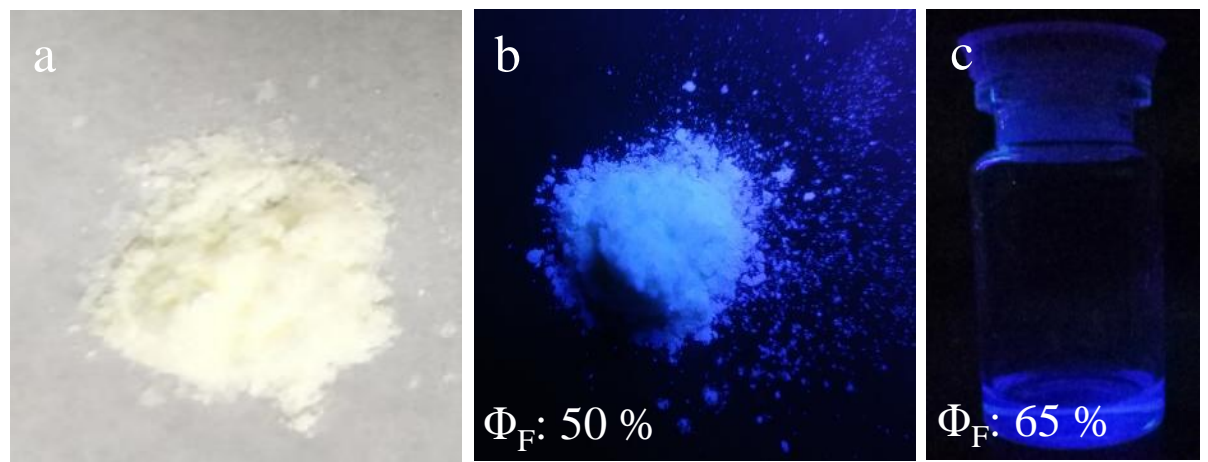

Figure S1. (a) Optical image of LD-1 powder purified through vacuum-sublimation process. (b) The fluorescence photographs of LD-1 powder and (c) LD-1 solution of dichloromethane $\left(10^{-5} \mathrm{M}\right.$ $\mathrm{L}^{-1}$ ) under illumination of a handheld UV (365 nm) lamp, respectively.

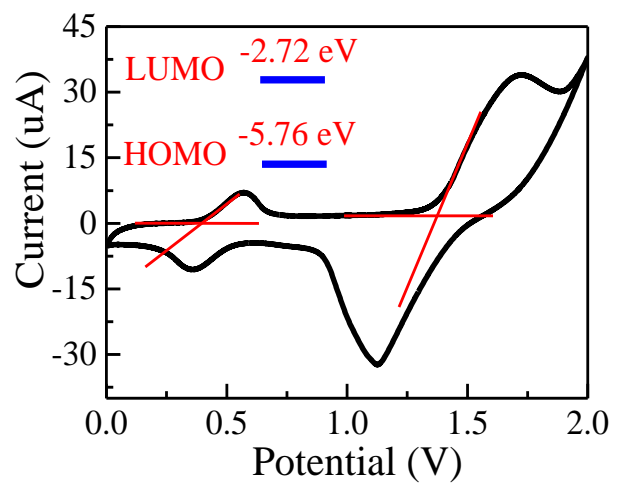

Figure S2. Cyclic Voltammogram of LD-1 in acetonitrile solution with sample concentration of $10^{-3} \mathrm{M}$ using $\mathrm{Bu}_{4} \mathrm{NPF}_{6}$ as electrolyte, and using $\mathrm{Pt}$ as working electrode, platinum wire as auxiliary electrode, a porous glass wick $\mathrm{Ag} / \mathrm{AgCl}$ as pseudo-reference electrode with the scan rate of $0.1 \mathrm{~V} \mathrm{~s}^{-1}$. 


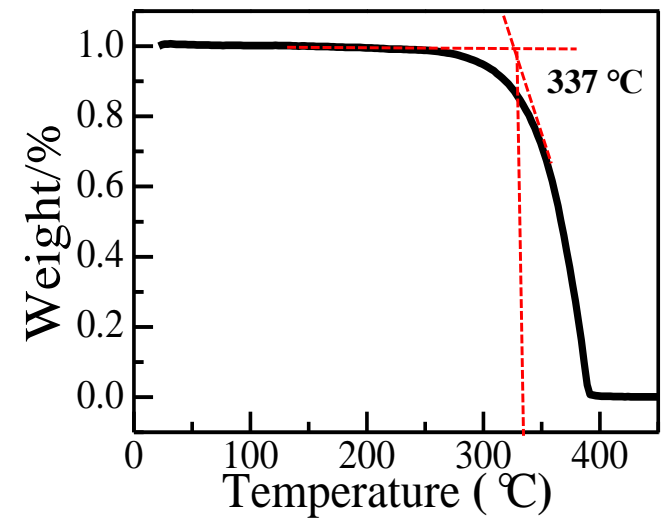

Figure S3. Thermal gravimetric analysis (TGA) of LD-1.
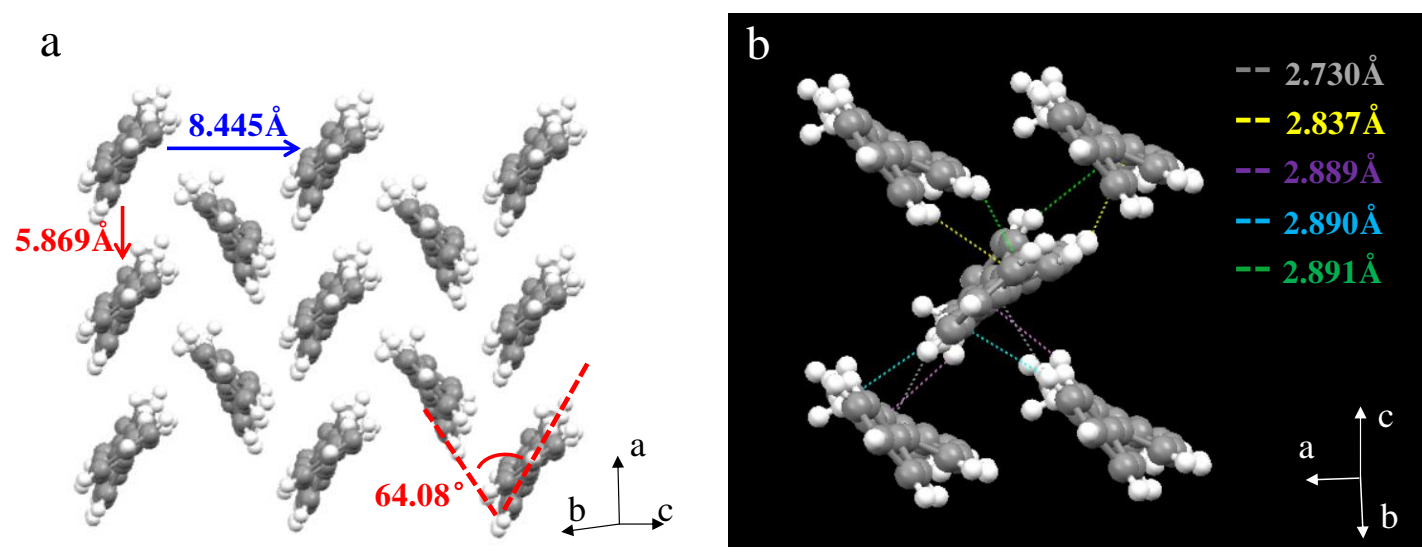

Figure S4. (a) Typical herringbone packing adopted by LD-1 molecular packing in crystals. (b) Multi-short intermolecular interactions shown by the dotted lines are formed for one LD-1 molecule with their neighboring four molecules.
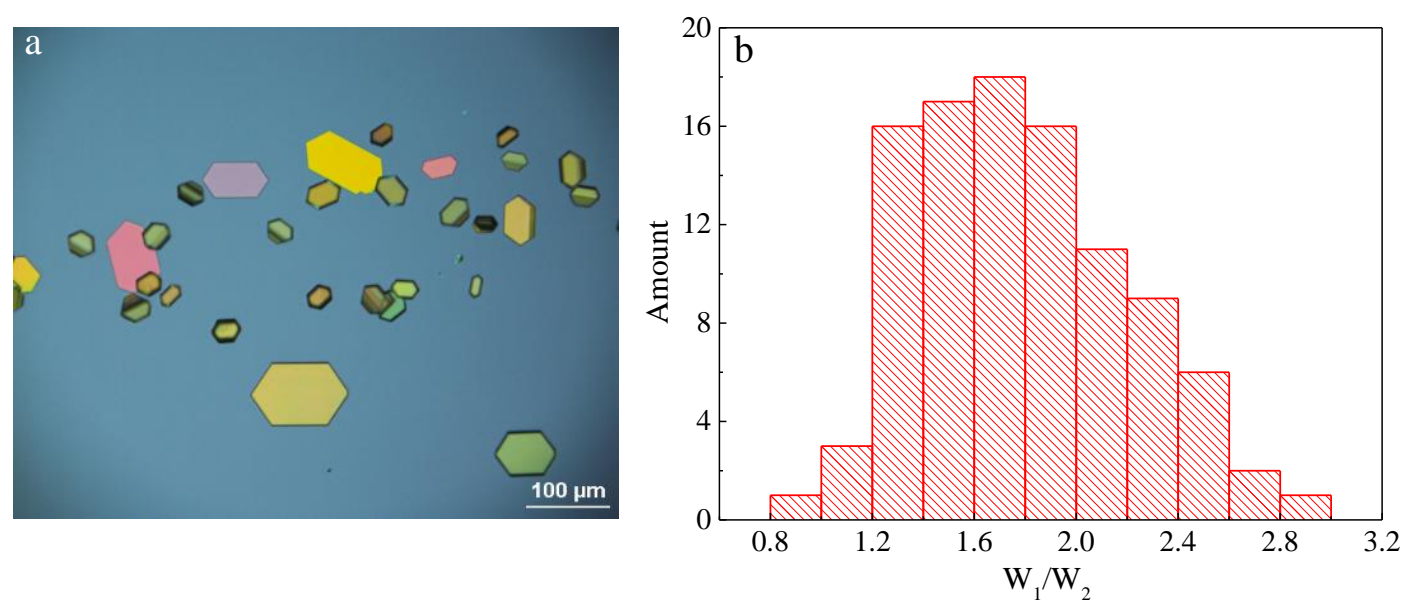

Figure S5. (a) Optical images of the LD-1 crystals, (b) Size distribution of the side-length $\left(\mathrm{W}_{1} / \mathrm{W}_{2}\right)$ of LD-1 crystals. The edge-length $\left(\mathrm{W}_{1} / \mathrm{W}_{2}\right)$ of LD-1 crystals are found to range between 1.2 and 2.0. 

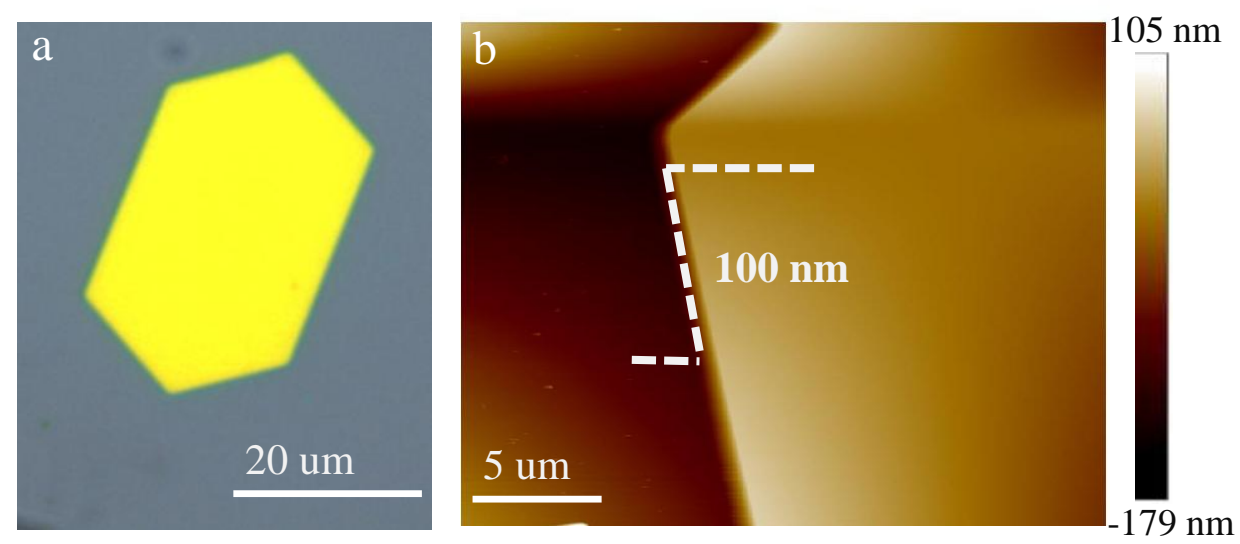

Figure S6. Optical microscopy image of LD-1 crystals (a) on the OTS-modified substrate by physical vapor transport and the corresponding AFM image (b).
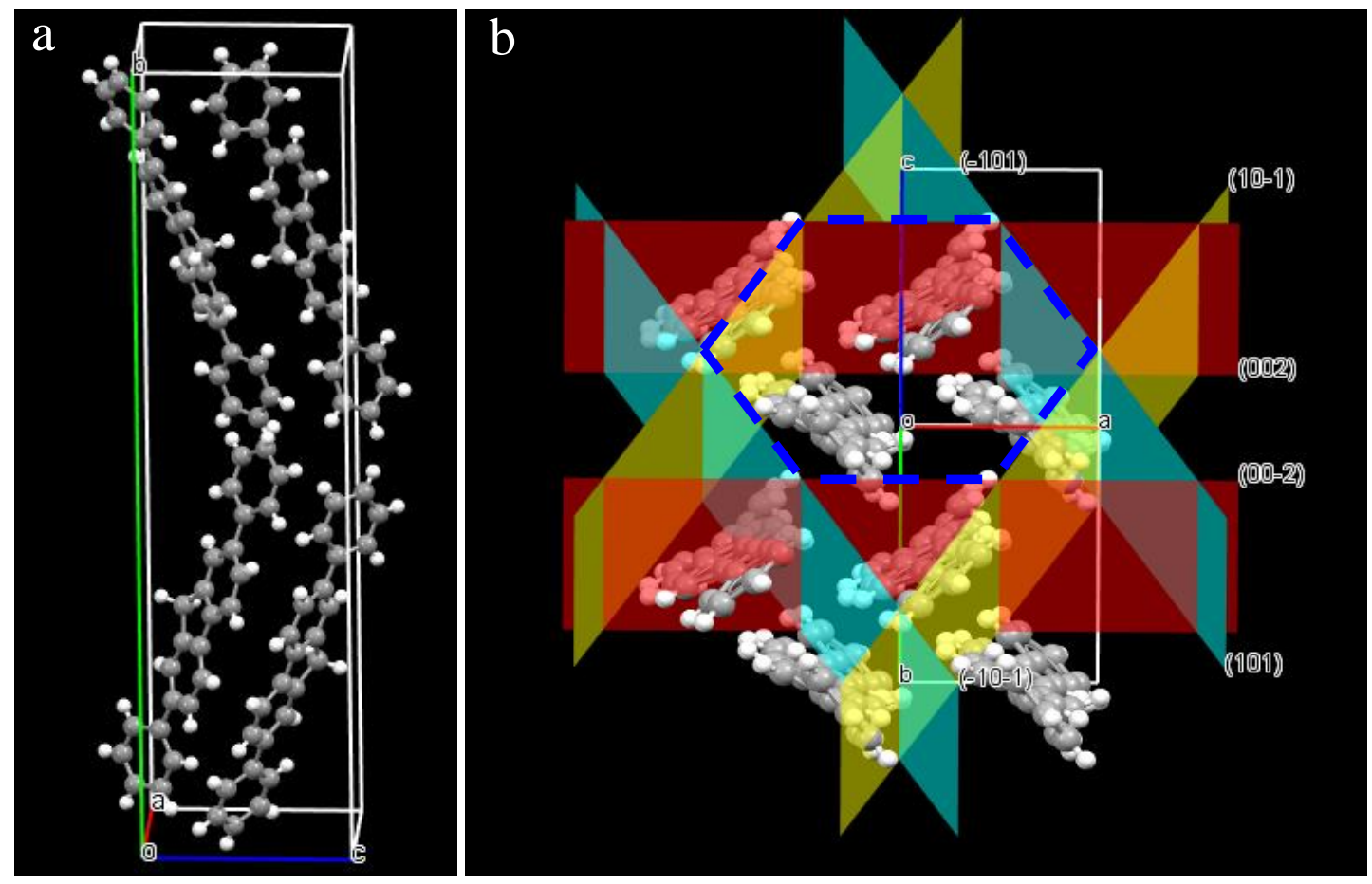

Figure S7. (a) A unit cell of orthorhombic LD-1 crystal. It can be seen that orthorhombic LD-1 crystal adopts a lamellar structure along the crystal $b$-axis. (b) The molecular packing arrangement within the layer of (010) plane. It can be seen that LD-1 molecules packed with herringbone structure. The LD-1 are single crystals bound by $(010)$ and $(0 \overline{1} 0)$ crystal planes on the top and bottom faces and by $(002),(00 \overline{2}),(\overline{1} 01),(10 \overline{1}),(101)$ and $(\overline{1} 0 \overline{1})$ crystal planes on the six side-faces (Figure 1d). 

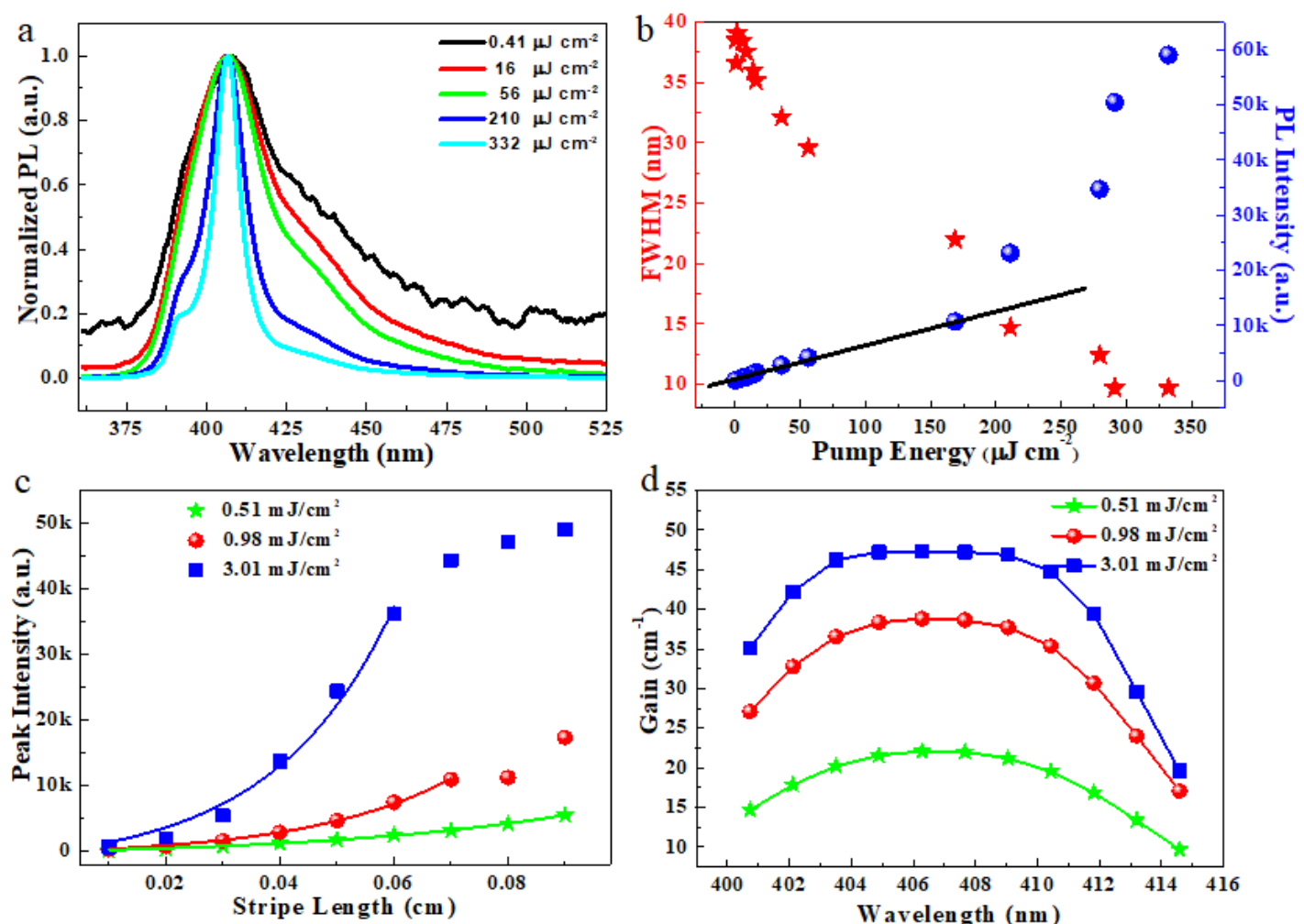

Figure S8. (a) Normalized PL spectra of the LD-1 crystal at different pump energies. (b) PL intensity and FWHM of the emission spectra for the LD-1 crystals on the pump laser energy. It can be seen that the FWHM of the PL spectra decreased from $39 \mathrm{~nm}$ to $9.66 \mathrm{~nm}$ as the pump energy gradually increased. The threshold of ASE can be extracted from the change of slope of the pump intensity dependence, which is located at $168 \mathrm{uJ} \mathrm{cm}^{-2}$. (c) Peak intensity of the emission as a function of pump stripe length for the LD-1 crystals under different pump energies. (d) The gain coefficients for the LD-1 crystals as a function of the wavelength. By fitting the intensity at different wavelengths of the PL spectrum as a function of stripe length, the highest gain coefficient of LD-1 crystal was $48 \mathrm{~cm}^{-1}$ at the pump energy of $3.01 \mathrm{~mJ} \mathrm{~cm}$, suggesting that the stimulated emission amplified most at $407 \mathrm{~nm}$ as the pump energy increasing.

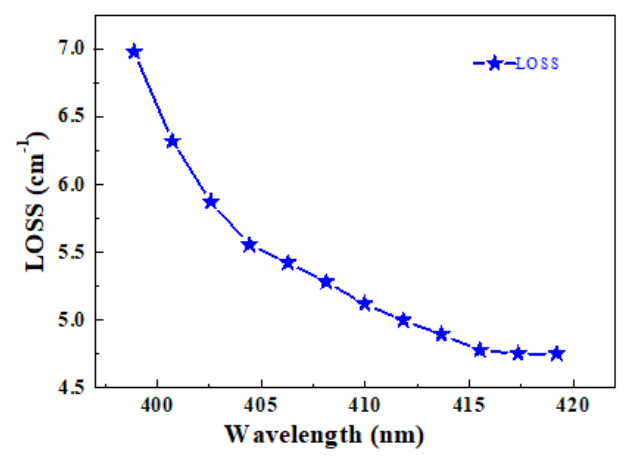

Figure S9. Loss coefficient for LD-1 crystal as a function of the wavelength. The loss coefficient is calculated as small as $5.29 \mathrm{~cm}^{-1}$ at the ASE peak, Usually, the optical loss is derived from scattering and reabsorption. 


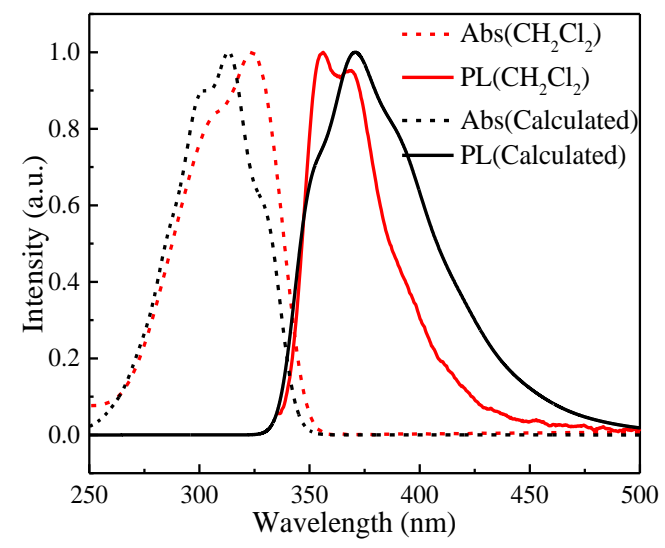

Figure S10. Theoretically calculated and experiment absorption and emission spectra in $\mathrm{CH}_{2} \mathrm{Cl}_{2}$ solution.
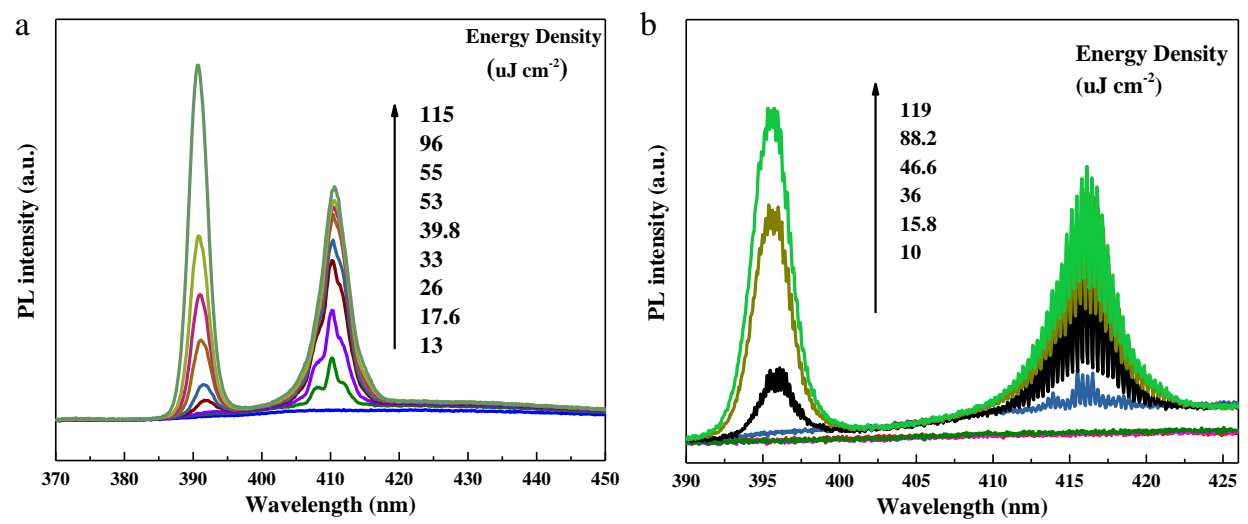

Figure S11. PL spectra (a) and high-resolution PL spectra (b) of the LD-1 single crystal under different pump densities at room temperature.

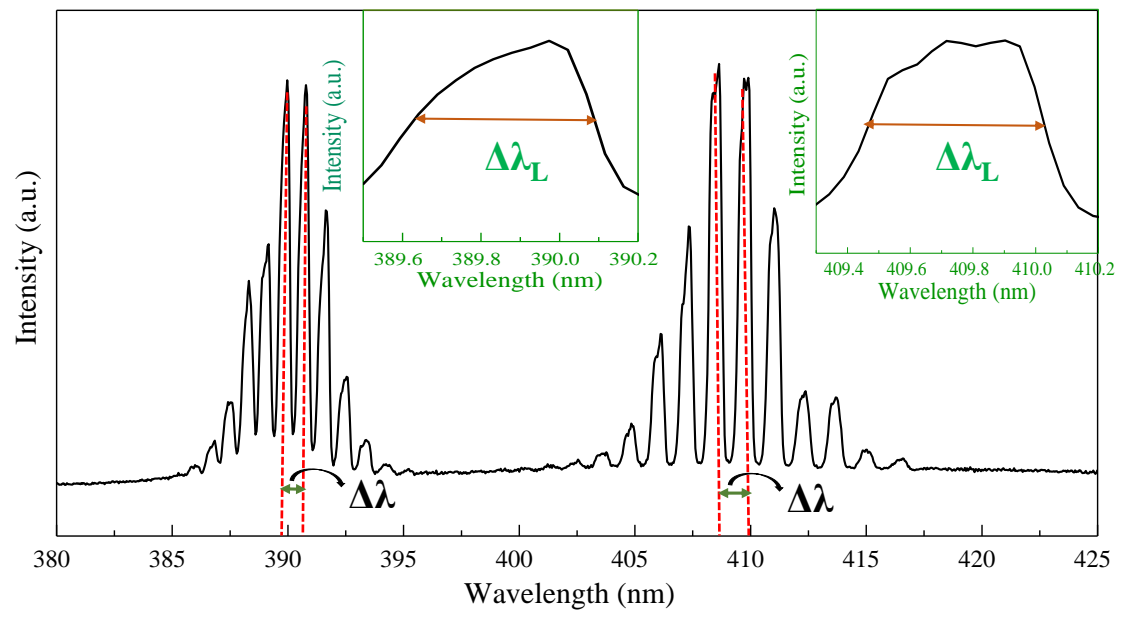

Figure S12. The PL spectra (black) and peak-separation-fitting spectra (red) of LD-1 single crystal at $390 \mathrm{~nm}$ and $410 \mathrm{~nm}$, inset: The $\Delta \lambda_{\mathrm{L}}$ is the line-width of the peak around $390 \mathrm{~nm}$ and 410 nm. 


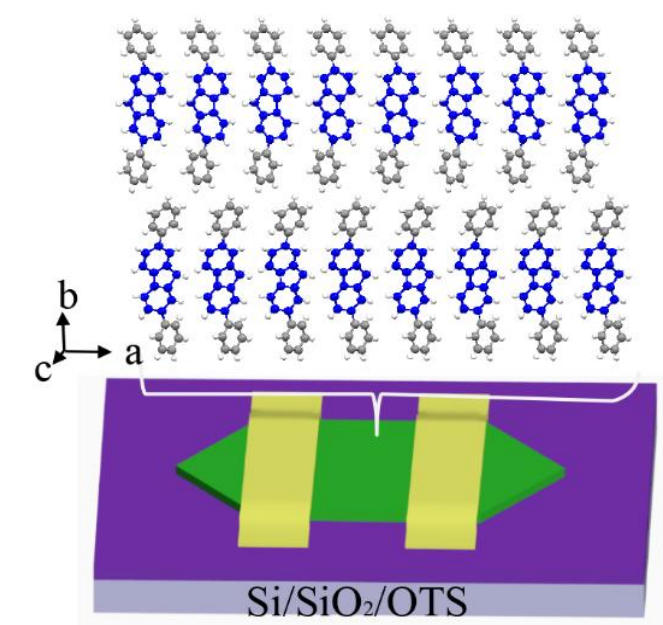

Figure S13. Schematic of LD-1 based transistor with bottom-gate top-contact device geometry.

a

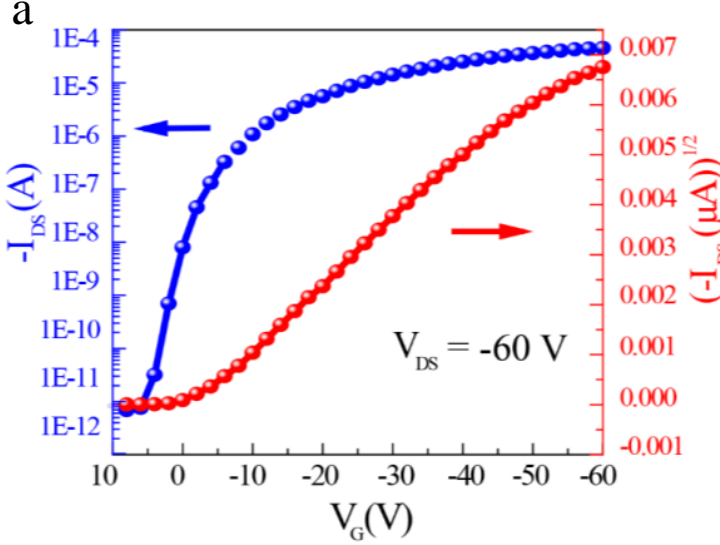

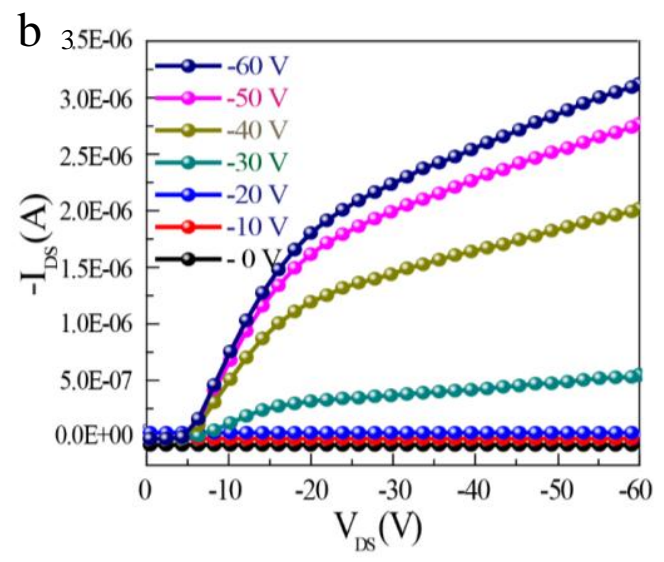

Figure S14. Typical transfer and output curves of LD-1 based OFET.

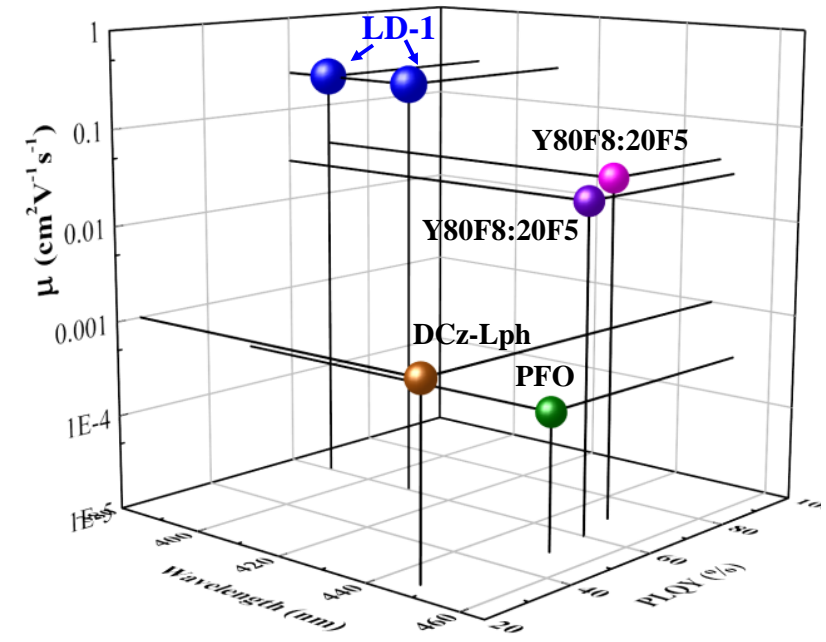

Figure S15. A summary of high-performance fluorene-based blue materials with lasing and mobility property previously reported in literature ${ }^{6,7}$ As a clear comparison, LD-1 is also shown here that shows the highest charge carrier mobility and deep-blue lasing character. 

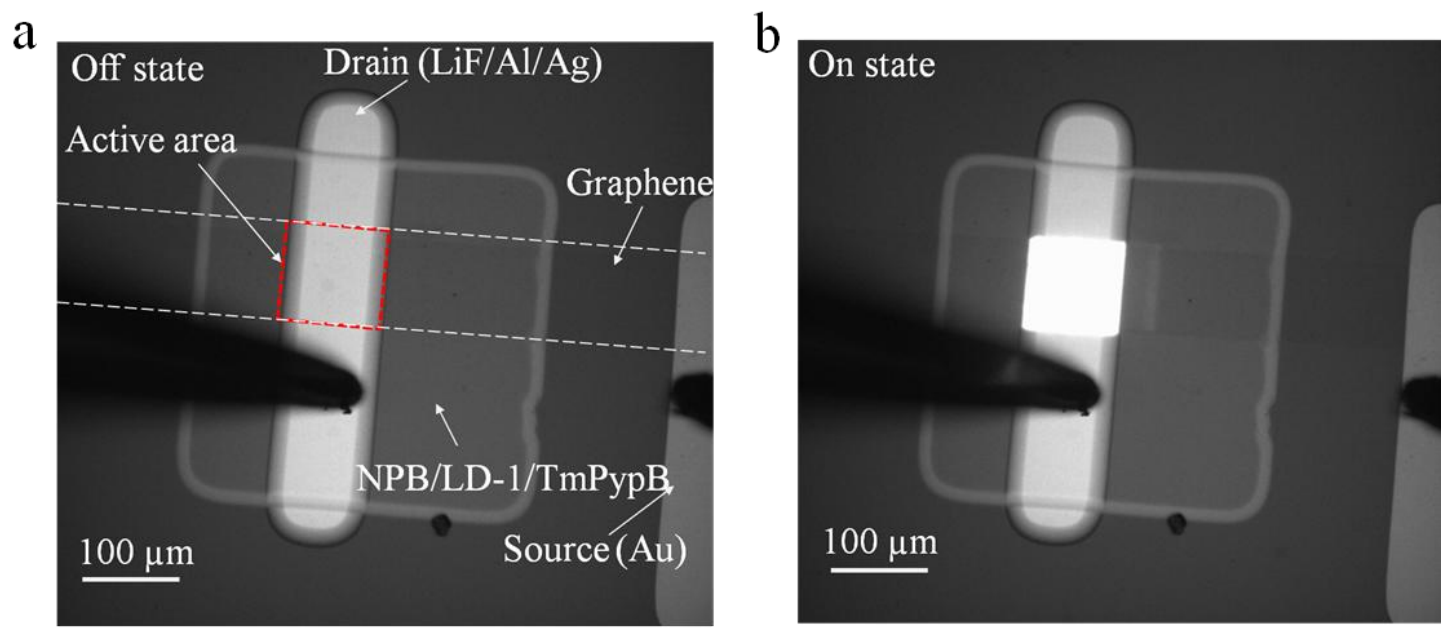

Figure S16. The CCD images of LD-1 OLET device captured under off-state and on-state.

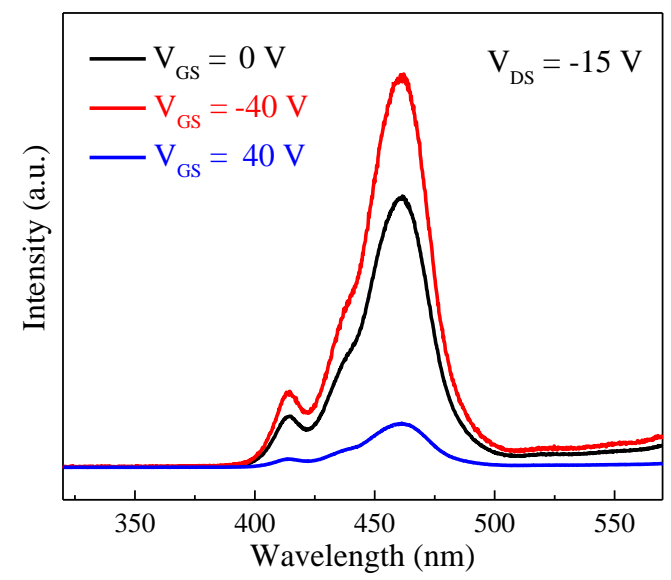

Figure S17. The electroluminescence spectra of LD-based OLETs at a fixed $\mathrm{V}_{\mathrm{DS}}$ of $-15 \mathrm{~V}$ and different $\mathrm{V}_{\mathrm{GS}}$.

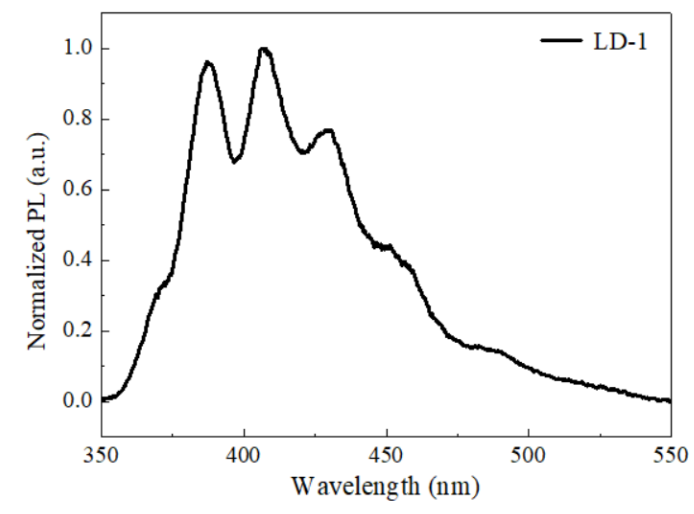

Figure S18. PL spectrum of vacuum-deposited LD-1 thin film (30 nm). 


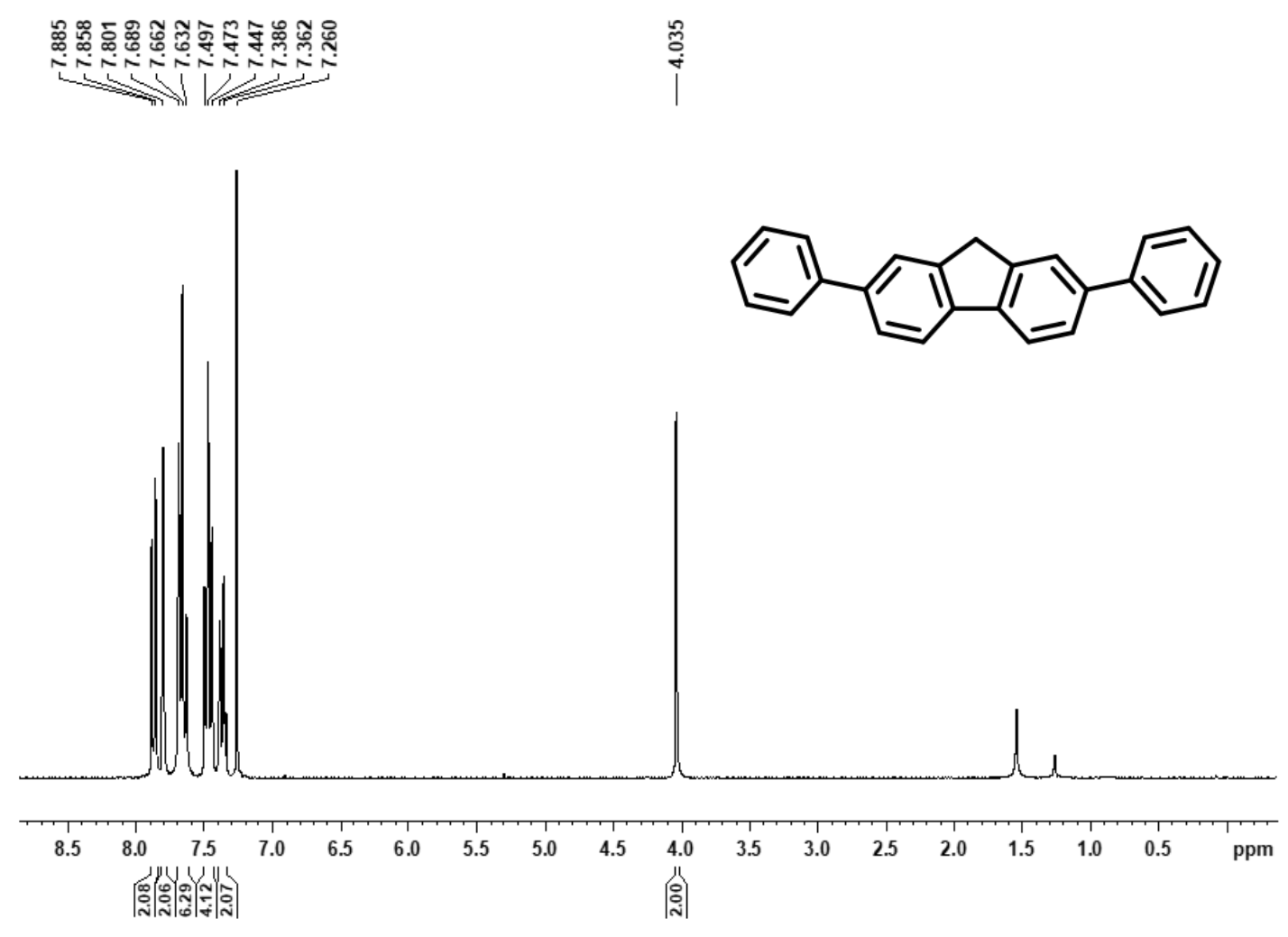

Figure S19. ${ }^{1}$ H NMR spectrum of LD-1 in deuterated chloroform.

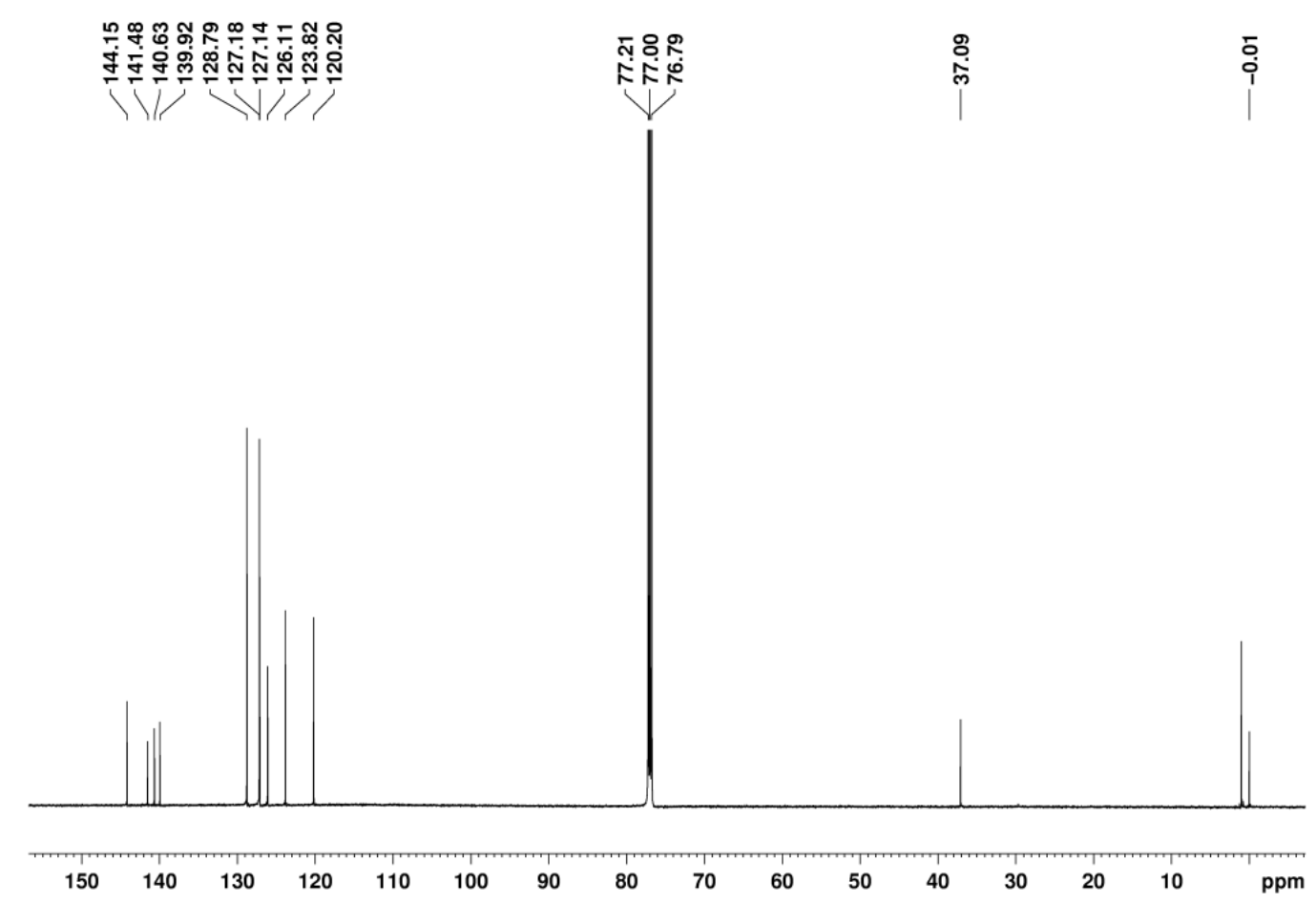

Figure S20. ${ }^{13} \mathrm{C}$ NMR spectrum of LD-1 in deuterated chloroform. 


\section{MALDI,DPF}

\section{Analysis Info}

Analysis Name

Method

Sample Name

Comment

Acquisition Parameter

Acquisition Mode Single MS

Polarity Positive

Broadband Low Mass $101.1 \mathrm{~m} / \mathrm{z}$

Broadband Low Mass $101.1 \mathrm{~m} / 2$

Broadband High Mass $600.0 \mathrm{~m} / \mathrm{z}$

$\begin{array}{ll}\text { Source Accumulation } & 0.001 \mathrm{sec} \\ \text { Ion Accumulation Time } & 0.300 \mathrm{sec}\end{array}$

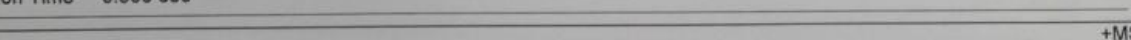

Intens
$\times 10^{7}$

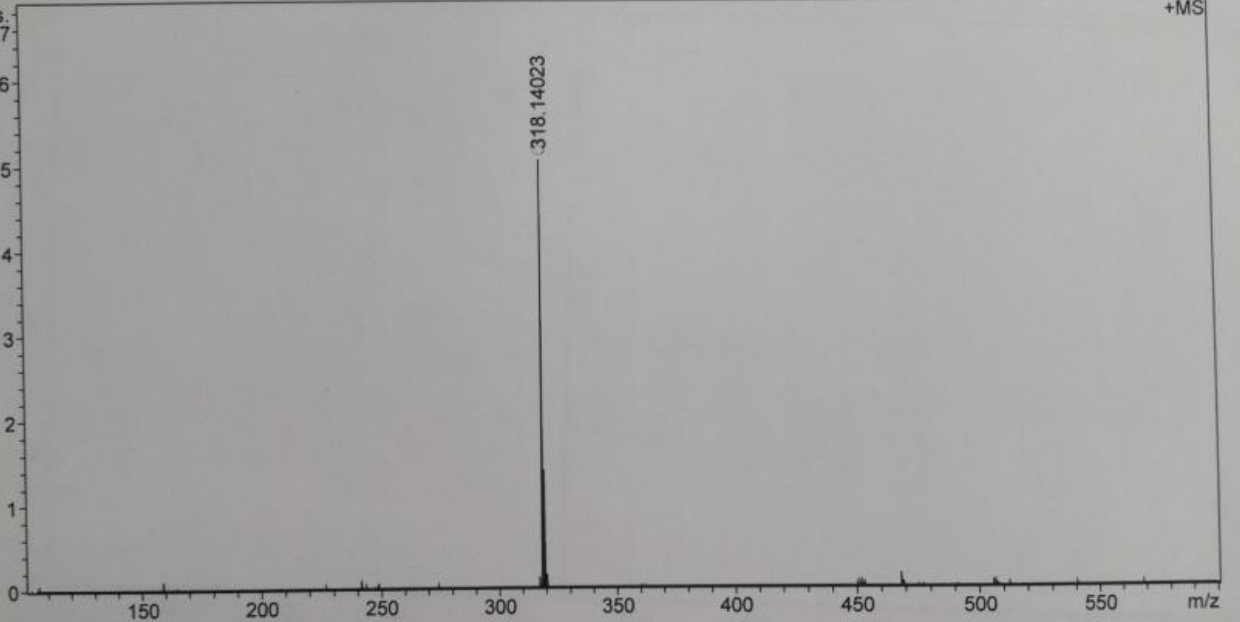

Acquired Scans 3

No. of Laser Shots

No. of Laser Shot

Fri Jan 17 04:38:06 2020 2097152

Apodization Sine-Bell Multiplication

Operator

Instrument

solariX

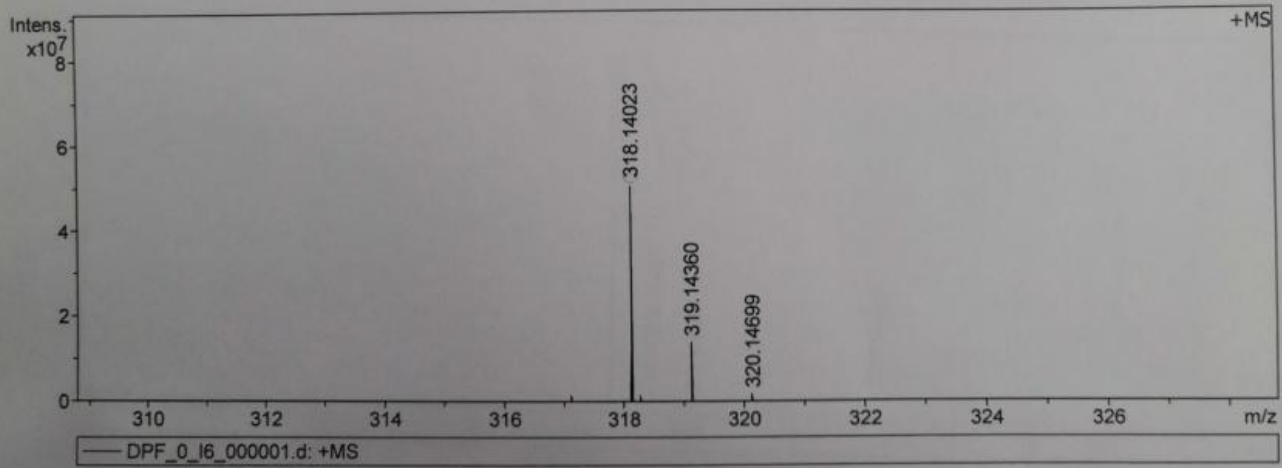

Meas. $\mathrm{m} / \mathrm{z}$ \# Ion Formula Score

$318.140229 \quad 1 \quad \mathrm{C} 25 \mathrm{H} 18$

$100.00 \quad 318.140302$ $\begin{array}{rrrrrrr}M / 2 & \text { err }[\mathrm{ppm}] & \text { Mean err [ppm] } & \text { mSigma } & \text { rdb } & \mathrm{e}^{-} \text {Conf } & \mathrm{N}-\mathrm{Rule} \\ -0.2 & 0.2 & 2.7 & 17.0 & \text { odd } & \text { ok }\end{array}$

Figure S21. High resolution mass spectrometry of LD-1. 
Table S1. A summary of optoelectronic performances for materials that integrate charge carrier transport and laser property.

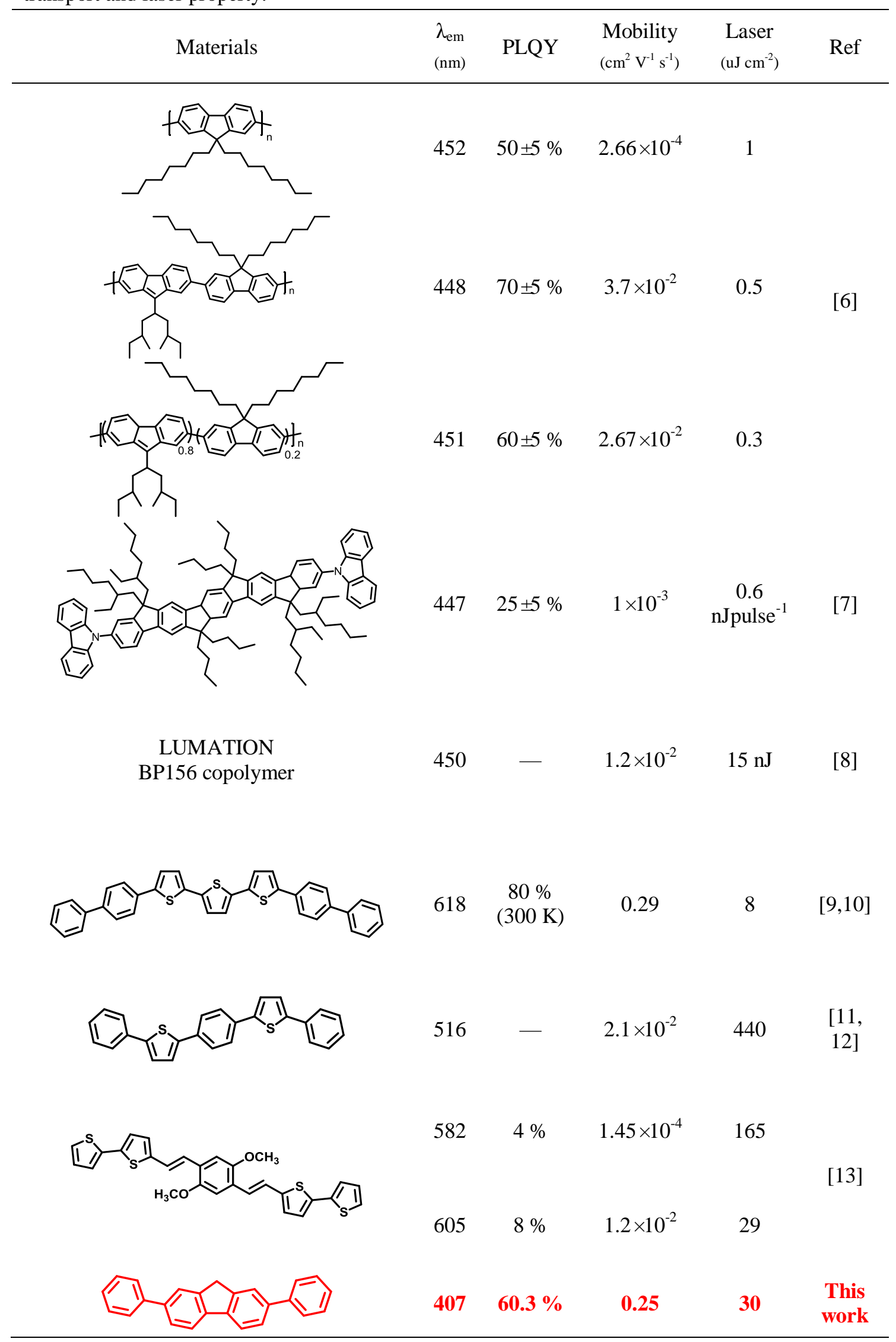


Table S2. A summary of device performances for organic field-effect transistors based on fluorene derivatives currently reported in literatures.

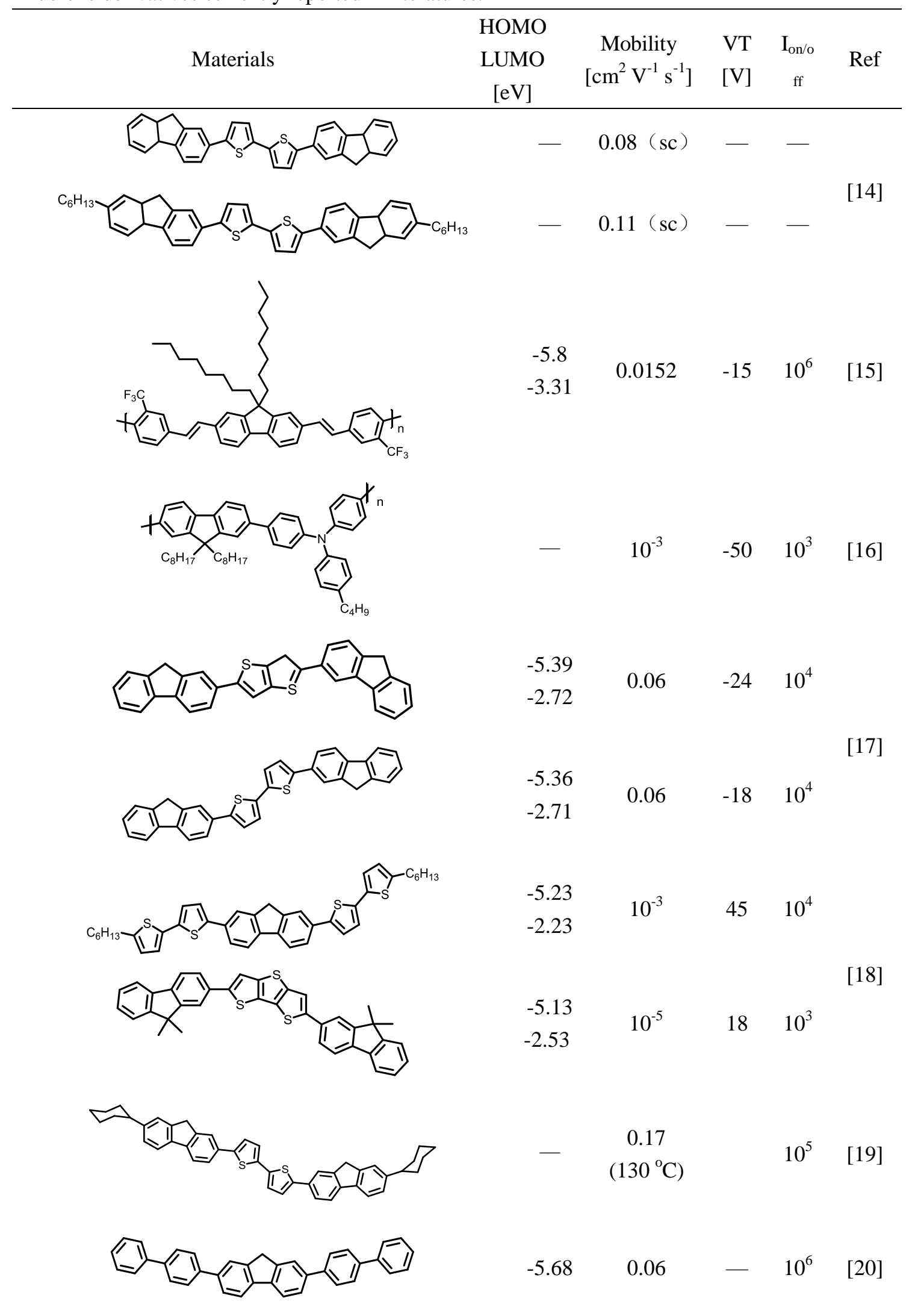




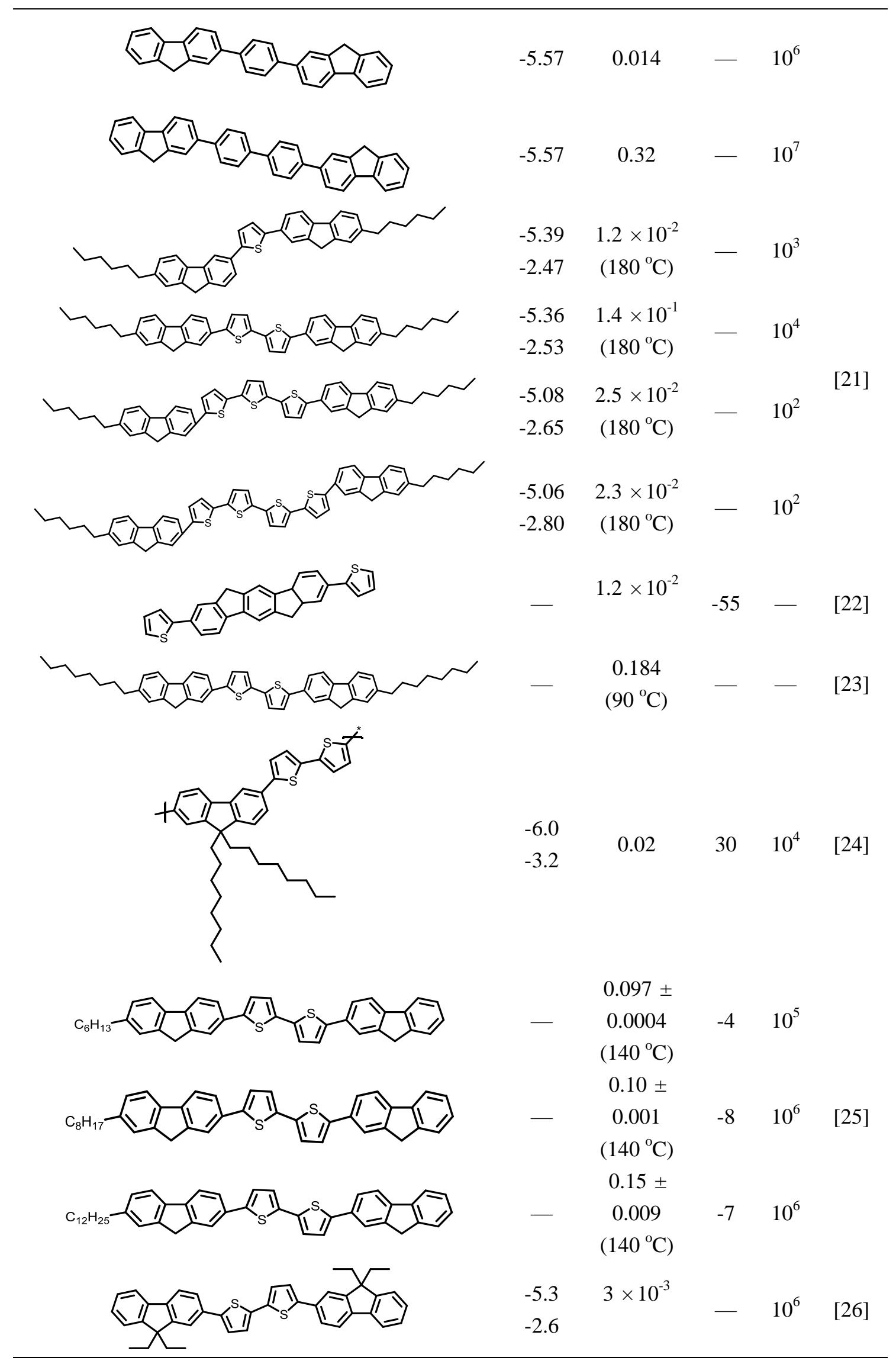




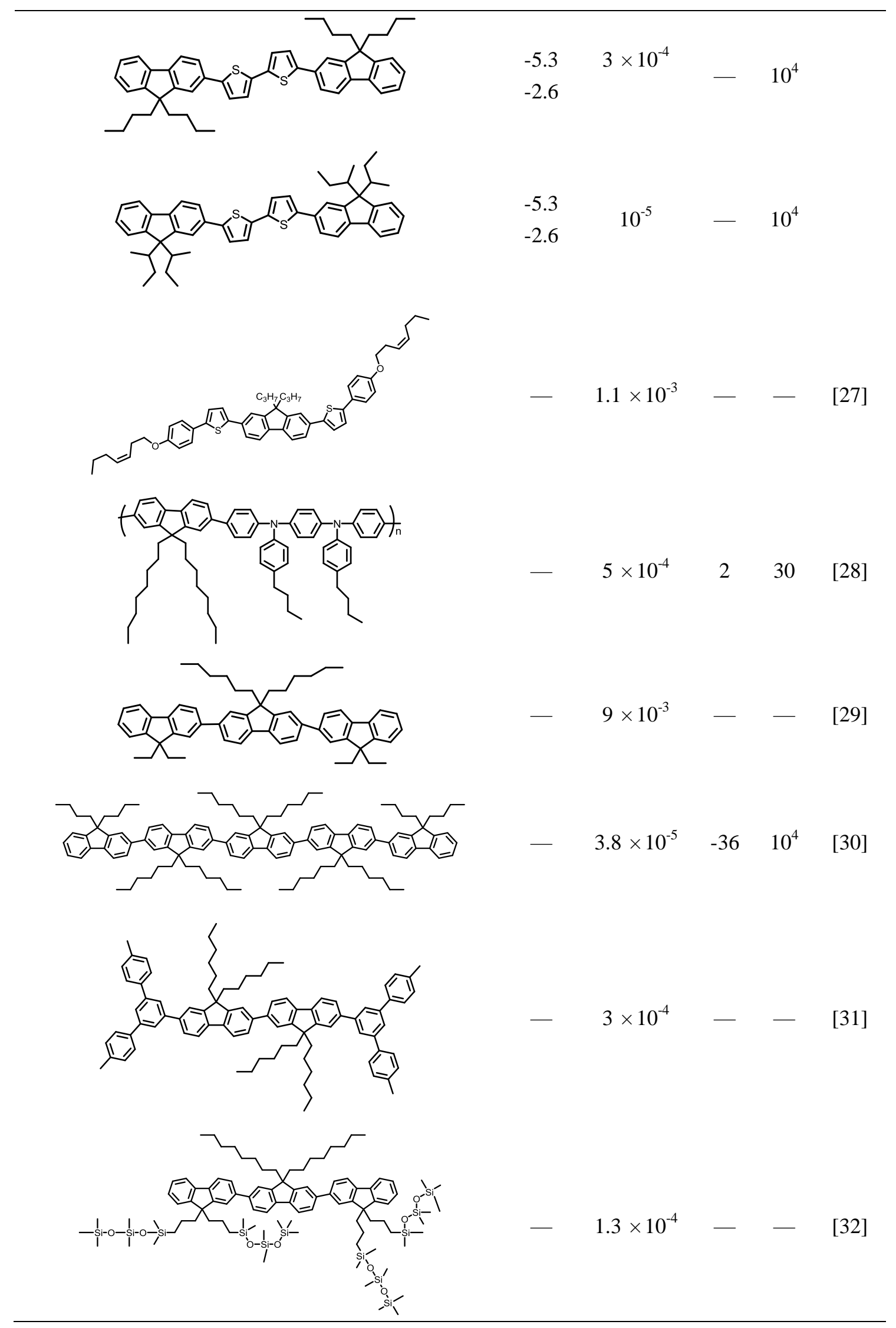




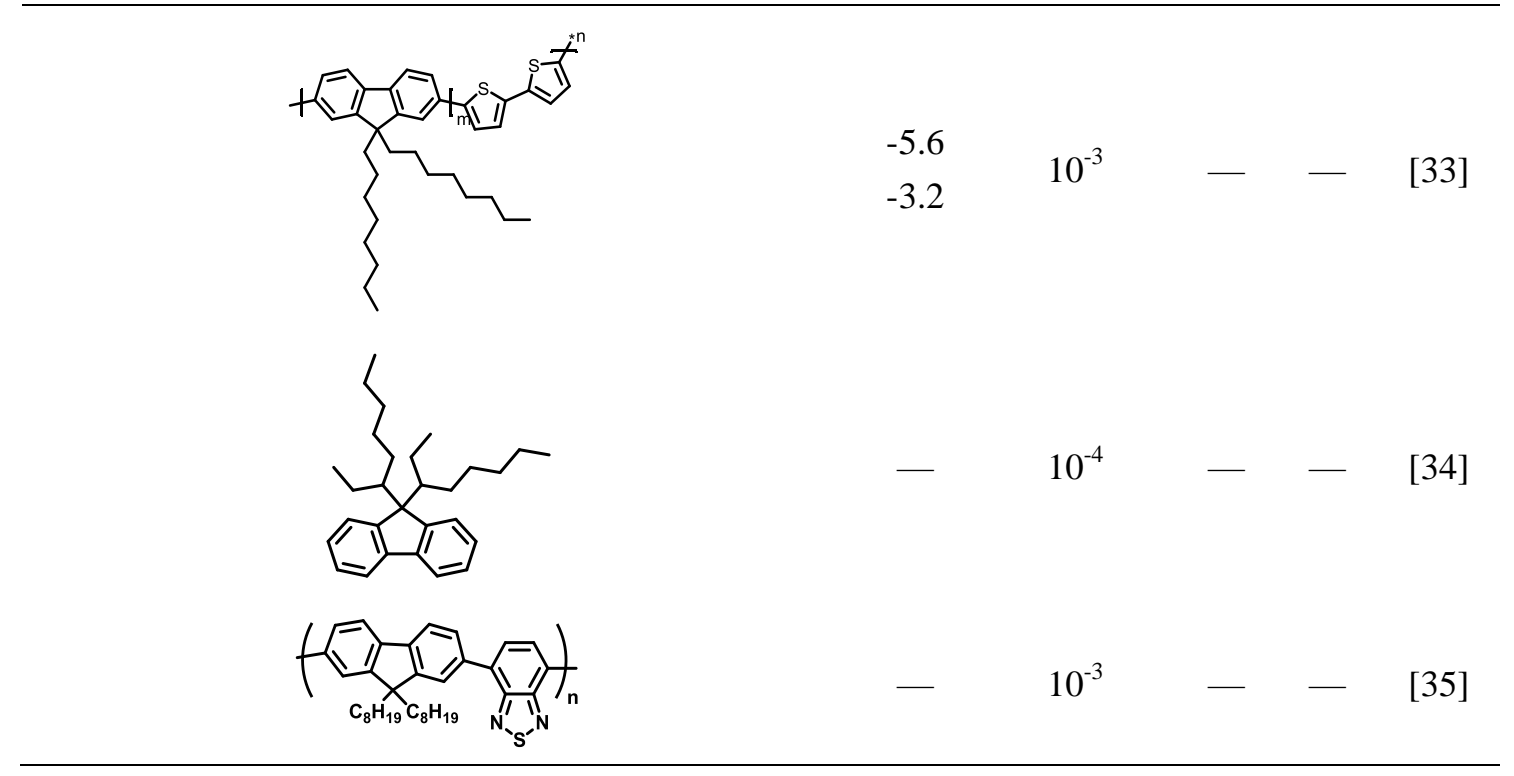


Table S3. Crystal Data and Structure Refinement for LD-1 (CCDC: 1942276).

\begin{tabular}{|c|c|}
\hline Parameters & LD-1 crystal \\
\hline Empirical formula & C25 H18 \\
\hline Formula weight & 318.39 \\
\hline Temperature & $169.99(10) \mathrm{K}$ \\
\hline Wavelength & $1.54184 \AA$ \\
\hline Crystal system & Orthorhombic \\
\hline Space group & P212121 \\
\hline & $a=5.8687(2) \AA, \alpha=90^{\circ}$ \\
\hline Unit cell dimensions & $b=33.6814(8) \AA, \beta=90^{\circ}$ \\
\hline & $c=8.4453(3) \AA, \gamma=90^{\circ}$ \\
\hline $\mathrm{Z}$ & 4 \\
\hline Density (calculated) & $1.267 \mathrm{~g} \mathrm{~cm}^{-3}$ \\
\hline Absorption coefficient & $0.541 \mathrm{~mm}^{-1}$ \\
\hline $\mathrm{F}(000)$ & 672 \\
\hline Crystal size $(\mathrm{mm})$ & $0.245 \times 0.21 \times 0.012 \mathrm{~mm}^{3}$ \\
\hline Theta range for data collection & $5.248^{\circ}$ to $151.154^{\circ}$ \\
\hline \multirow[t]{3}{*}{ Index ranges } & $-5<=h<=7$ \\
\hline & $-42<=\mathrm{k}<=42$ \\
\hline & $-9<=1<=10$ \\
\hline Reflections collected & 15006 \\
\hline Independent reflections & 3274 \\
\hline Rint & 0.0721 \\
\hline Completeness to theta & None \\
\hline Absorption correction & None \\
\hline Max. and min. transmission & None \\
\hline Data/ restraints / parameters & $3276 / 0 / 224$ \\
\hline Goodness-of-fit on F2 & 1.086 \\
\hline \multirow{2}{*}{ Final $R$ indices $[\mathrm{I}>2 \operatorname{sigma}(\mathrm{I})]$} & $\mathrm{R} 1=0.0734$ \\
\hline & $\mathrm{wR} 2=0.1804$ \\
\hline \multirow{2}{*}{$\mathrm{R}$ indices (all data) } & $\mathrm{R} 1=0.0833$ \\
\hline & $w R 2=0.1875$ \\
\hline Largest diff. peak and hole & 0.3 and -0.3 e. $\AA^{-3}$ \\
\hline
\end{tabular}


Table S4. Time-resolved PL measurements of LD-1 in dilute dichloromethane solution (A) and single crystals (B).

$\begin{array}{ll}\text { (A) In solution } \tau=2.83 \mathrm{~ns} & \text { (B) Crystals } \tau=1.90 \mathrm{~ns} \\ \tau_{1}=2.15 \mathrm{~ns}(96.49 \%) & \tau_{1}=1.37 \mathrm{~ns}(51.45 \%) \\ \tau_{2}=21.6 \mathrm{~ns}(3.51 \%) & \tau_{2}=2.47 \mathrm{~ns}(48.55 \%)\end{array}$

The lifetime was calculated using the approximation formula $\tau \approx \tau_{1} \times$ percentage of $\tau_{1}(\%)+\tau_{2} \times$ percentage of $\tau_{2}(\%) \cdots \cdots$.

Table S5. Theoretical and experimental rate constants and photoluminescence quantum yield of LD-1 molecule in $\mathrm{CH}_{2} \mathrm{Cl}_{2}$ solution.

\begin{tabular}{cccc}
\hline LD-1 & $\mathrm{k}_{\mathrm{r}}\left[\mathrm{s}^{-1}\right]$ & $\mathrm{k}_{\mathrm{nr}}\left[\mathrm{s}^{-1}\right]$ & $\Phi_{\mathrm{F}}$ \\
\hline Theoretical & $8.92 \times 10^{8}$ & $4.91 \times 10^{8}$ & 0.64 \\
Experimental & $2.30 \times 10^{8}$ & $1.24 \times 10^{8}$ & 0.65 \\
\hline
\end{tabular}

Table S6. A summary of quality factor (Q) for some representative organic laser materials reported in literatures (Microcavity of species: whispering-gallery-mode (WGM) and Fabry-Perot (FP)).

\begin{tabular}{cccccc}
\hline Material & $\lambda_{\text {em }}(\mathrm{nm})$ & PLQY & microcavity & $\begin{array}{c}\text { quality } \\
\text { factor (Q) }\end{array}$ & Ref \\
\hline mp-PDI & 600 & $15 \%$ & WGM & 567 & {$[36]$} \\
TPDSB & 520 & $85 \%$ & FP & 2565 & {$[37]$} \\
HBT & 520 & $68 \%$ & FP & 1500 & {$[38]$} \\
CAZ-A doped CBP & 640 & $60 \%$ & WGM & 1300 & {$[39]$} \\
DSB & 475 & $65 \%$ & WGM & 210 & {$[40]$} \\
DPHP & 650 & $15 \%$ & WGM & 1400 & {$[41]$} \\
DPFOH:PMMA-coated & 385 & $38 \%$ & WGM & 2000 & {$[42]$} \\
BP1T & 496 & - & WGM & 1066 & {$[43]$} \\
mp-PDI & 580 & $18 \%$ & FP & 825 & {$[44]$} \\
OCBzC & 539 & - & WGM & 2700 & {$[45]$} \\
BF2AVB & 461 & $68 \%$ & FP & 985 & {$[46]$} \\
\hline
\end{tabular}




\begin{tabular}{cccccc}
\hline & 407 & $83 \%$ & FP & 786 & \\
TDMeF & 412 & $80 \%$ & FP & 1144 & [47] \\
& 582 & $4 \%$ & FP & 1000 & \\
TPDSB & 605 & $8 \%$ & WGM & 1600 & {$[13]$} \\
DPHP & 650 & $11 \%$ & WGM & 880 & {$[48]$} \\
AC5 & 516 & - & - & 24500 & {$[11]$} \\
BP3T & 618 & $80 \%(300 \mathrm{~K})$ & FP & 1700 & {$[49]$} \\
LD-1 & 390 & $60.3 \%$ & WGM & $\mathbf{3 1 0 0}$ & This work \\
\hline
\end{tabular}

\section{Reference}

[1] Frisch, M. J. Gaussian 16 Rev. C.01. Wallingford, CT, 2016.

[2] Zhao, Y.; Truhlar, D. G. "The M06 suite of density functionals for main group thermochemistry, thermochemical kinetics, noncovalent interactions, excited states, and transition elements: two new functionals and systematic testing of four M06-class functionals and 12 other functionals" Theory. Chem. Acc. 2008, 120, 215-241.

[3] Vreven, T.; Morokuma, K. Hybrid Methods: ONIOM(QM:MM) and QM/MM. Annual Reports in Computational Chemistry. 2006, 2, 35-49.

[4] MOMAP - Molecular Material Property Prediction Package. http://www.momap.net.cn.

[5] Sprick, R. S.; Bonillo, B.; Clowes, R.; Guiglion, P.; Brownbill, N. J.; Slater, B. J.; Blanc, F.; Zwijnenburg, M. A.; Adams, D. J.; Cooper, A. I. Visible-light-driven hydrogen evolution using planarized conjugated polymer photocatalysts. Angew. Chem., Int. Ed. 2016, 128, 1824 -1828 .

[6] Yap, B. K.; Xia, R.; Campoy-Quiles, M.; Stavrinou, P. N.; Bradley, D. D. C. Simultaneous optimization of charge-carrier mobility and optical gain in semiconducting polymer films. Nat. Mater. 2008, 7, 376-380.

[7] Wei, Q.; Li, Y.; Liu, J.; Fang, Q.; Li, J.; Yan, X.; Xie, L.; Qian, Y.; Xia, R.; Huang, W. A High performance deep blue organic laser gain material. Adv. Opt. Mater. 2017, 5, 160100.

[8] Heliotis, G.; Choulis, S. A.; Itskos, G.; Xia, R.; Murray, R.; Stavrinou, P. N.; Bradley, D. D. C. Low-threshold lasers based on a high-mobility semiconducting polymer. Appl. Phys. Lett. 2006, $88,081104$.

[9] Nakamura, K.; Ichikawa, M.; Fushiki, R.; Kamikawa, T.; Inoue, M.; Koyama, T.; Taniguchi, Y. Light emission from organic single-crystal field-effect transistors. Jpn. J. Appl. Phys. 2005, 44, L1367-L1369.

[10] Ichikawa, M.; Nakamura, K.; Inoue, M.; Mishima, H.; Haritani, T.; Hibino, R.; Koyama, T.; Taniguchi, Y. Photopumped laser oscillation and charge-injected luminescence from organic semiconductor single crystals of a thiophene/phenylene co-oligomer. Appl. Phys. Lett. 2005, $87,221113$. 
[11] Yamao, T.; Yamamoto, K.; Taniguchi, Y.; Miki, T.; Hotta, S. Laser oscillation in a highly anisotropic organic crystal with a refractive index of 4.0. J. Appl. Phys. 2008, 103, 4.

[12] Yamao, T.; Ota, S.; Miki, T.; Hotta, S.; Azumi, R. Improved sublimation growth of single crystals of thiophene/phenylene co-oligomers. Thin Solid Films 2008, 516, 2527-2531.

[13] Liao, Q.; Wang, Z.; Gao, Q.; Zhang, Z.; Ren, J.; De, J.; Zhang, X.; Xu, Z.; Fu, H. The effect of 1D- and 2D-polymorphs on organic single-crystal optoelectronic devices: lasers and field effect transistors. J. Mater. Chem. C 2018, 6, 7994-8002.

[14] Meng, H.; Bao, Z.; Lovinger, A. J.; Wang, B. C.; Mujsce, A. M. High field-effect mobility oligofluorene derivatives with high environmental stability. J. Am. Chem. Soc. 2001, 123, 9214-9215.

[15] Chaing, C. J.; Chen, J. C.; Kuo, Y. J.; Tsao, H. Y.; Wu, K. Y.; Wang, C. L. 2,2 '-Bis(trifluoromethyl)biphenyl as a building block for highly ambient-stable, amorphous organic field-effect transistors with balanced ambipolarity. Rsc Adv. 2016, 6, 8628-8638.

[16] Yan, H.; Yoon, M. H.; Facchetti, A.; Marks, T. J. Organic field-effect transistors based on a crosslinkable polymer blend as the semiconducting layer. Appl. Phys. Lett. 2005, 87, 3.

[17] Noh, Y. Y.; Azumi, R.; Goto, M.; Jung, B. J.; Lim, E.; Shim, H. K.; Yoshida, Y.; Yase, K.; Kim, D. Y. Organic field effect transistors bBased on biphenyl, fluorene end-capped fused bithiophene oligomers. Chem. Mater. 2005, 17, 3861-3870.

[18] Porzio, W.; Destri, S.; Giovanella, U.; Pasini, M.; Marin, L.; Iosip, M. D.; Campione, M. Solid state properties of oligomers containing dithienothiophene or fluorene residues suitable for field effect transistor devices. Thin Solid Films 2007, 515, 7318-7323.

[19] Locklin, J.; Li, D.; Mannsfeld, S. C. B.; Borkent, E. J.; Meng, H.; Advincula, R.; Bao, Z. Organic thin film transistors based on cyclohexyl-substituted organic semiconductors. Chem. Mater. 2005, 17, 3366-3374.

[20] Locklin, J.; Ling, M. M.; Sung, A.; Roberts, M. E.; Bao, Z. High-performance organic Semiconductors based on fluorene-phenylene oligomers with high ionization potentials. $A d v$. Mater. 2006, 18, 2989-2992.

[21] Meng, H.; Zheng, J.; Lovinger, A. J.; Wang, B. C.; Van Patten, P. G.; Bao, Z. Oligofluorene-Thiophene Derivatives as High-performance semiconductors for organic thin film transistors. Chem. Mater. 2003, 15, 1778-1787.

[22] Py, C.; Gorjanc, T. C.; Hadizad, T.; Zhang, J.; Wang, Z. Y. Hole mobility and electroluminescence properties of a dithiophene indenofluorene. J. Vac. Sci. Technol. A 2006, 24, 654-656.

[23] Shin, T. J.; Yang, H.; Ling, M. m.; Locklin, J.; Yang, L.; Lee, B.; Roberts, M. E.; Mallik, A. B.; Bao, Z. Tunable thin-film crystalline structures and field-effect mobility of oligofluorene-thiophene derivatives. Chem. Mater. 2007, 19, 5882-5889.

[24] Sirringhaus, H.; Wilson, R. J.; Friend, R. H.; Inbasekaran, M.; Wu, W.; Woo, E. P.; Grell, M.; Bradley, D. D. C. Mobility enhancement in conjugated polymer field-effect transistors through chain alignment in a liquid-crystalline phase. Appl. Phys. Lett. 2000, 77, 406-408.

[25] Tang, M. L.; Roberts, M. E.; Locklin, J. J.; Ling, M. M.; Meng, H.; Bao, Z. Structure property relationships: asymmetric oligofluorene-thiophene molecules for organic TFTs. Chem. Mater. 2006, 18, 6250-6257.

[26] Thiem, H.; Strohriegl, P.; Setayesh, S.; de Leeuw, D. New fluorene-bithiophene-based trimers as stable materials for OFETs. Synth. Met. 2006, 156, 582-589. 
[27] Woon, K. L.; Aldred, M. P.; Vlachos, P.; Mehl, G. H.; Stirner, T.; Kelly, S. M.; O'Neill, M. Electronic charge transport in extended nematic liquid crystals. Chem. Mater. 2006, 18, 2311-2317.

[28] Adil, D.; Ukah, N. B.; Gupta, R. K.; Ghosh, K.; Guha, S. Interface-controlled pulsed-laser deposited polymer films in organic devices. Synth. Met. 2010, 160, 2501-2504.

[29] Baronas, P.; Kazlauskas, K.; Kreiza, G.; Jankauskas, V.; Tomkeviciene, A.; Simokaitiene, J.; Grigalevicius, S.; Grazulevicius, J. V.; Jursenas, S. Differently linked fluorene-carbazole triads for light amplification. Dyes and Pigments 2015, 123, 370-379.

[30] Choi, E. Y.; Mazur, L.; Mager, L.; Gwon, M.; Pitrat, D.; Mulatier, J. C.; Monnereau, C.; Fort, A.; Attias, A. J.; Dorkenoo, K.; Kwon, J. E.; Xiao, Y.; Matczyszyn, K.; Samoc, M.; Kim, D. W.; Nakao, A.; Heinrich, B.; Hashizume, D.; Uchiyama, M.; Park, S. Y.; Mathevet, F.; Aoyama, T.; Andraud, C.; Wu, J. W.; Barsella, A.; Ribierre, J. C. Photophysical, amplified spontaneous emission and charge transport properties of oligofluorene derivatives in thin films. Phys. Chem. Chem. Phys. 2014, 16, 16941-16956.

[31] Markham, J. P. J.; Anthopoulos, T. D.; Samuel, I. D. W.; Richards, G. J.; Burn, P. L.; Im, C.; Bassler, H. Nondispersive hole transport in a spin-coated dendrimer film measured by the charge-generation-layer time-of-flight method. Appl. Phys. Lett. 2002, 81, 3266-3268.

[32] Ribierre, J. C.; Zhao, L.; Inoue, M.; Schwartz, P. O.; Kim, J. H.; Yoshida, K.; Sandanayaka, A. S. D.; Nakanotani, H.; Mager, L.; Méry, S.; Adachi, C. Low threshold amplified spontaneous emission and ambipolar charge transport in non-volatile liquid fluorene derivatives. Chem. Commun. 2016, 52, 3103-3106.

[33] Ahles, M.; Hepp, A.; Schmechel, R.; von Seggern, H. Light emission from a polymer transistor. Appl. Phys. Lett. 2004, 84, 428-430.

[34] Campbell, A. J.; Bradley, D. D. C.; Antoniadis, H. Dispersive electron transport in an electroluminescent polyfluorene copolymer measured by the current integration time-of-flight method. Appl. Phys. Lett. 2001, 79, 2133-2135.

[35] Ohtsuka, Y.; Ishizumi, A.; Yanagi, H. Light-emitting field-effect transistors with pi-conjugated liquid crystalline polymer driven by AC-gate voltages. Org. Electron. 2012, 13, $1710-1715$.

[36] Yu, Z.; Wu, Y.; Liao, Q.; Zhang, H.; Bai, S.; Li, H.; Xu, Z.; Sun, C.; Wang, X.; Yao, J.; Fu, H. Self-assembled microdisk lasers of perylenediimides. J. Am. Chem. Soc. 2015, 137, 15105-15111.

[37] Wei, G.; Tao, Y.; Wu, J.; Li, Z.; Zhuo, M.; Wang, X.; Liao, L. Low-threshold organic lasers based on single-crystalline microribbons of aggregation-induced emission luminogens. J. Phys. Chem. Lett. 2019, 10, 679-684.

[38] Zhang, W.; Yan, Y.; Gu, J.; Yao, J.; Zhao, Y. Low-threshold wavelength-switchable organic nanowire lasers based on excited-state intramolecular proton transfer. Angew. Chem., Int. Ed. 2015, 54, 1- 6 .

[39] Huang, H.; Yu, Z.; Zhou, D.; Li, S.; Fu, L.; Wu, Y.; Gu, C.; Liao, Q.; Fu, H. Wavelength-tunable organic microring laser arrays from thermally activated delayed fluorescent emitters. ACS Photonics. 2019, 6, 3208-3214. 
[40] Wang, X.; Liao, Q.; Kong, Q.; Zhang, Y.; Xu, Z.; Lu, X.; Fu, H. Whispering-gallery-mode microlaser based on self-assembled organic single-crystalline hexagonal microdisks. Angew. Chem., Int. Ed. 2014, 53, 5863-5867.

[41] Wang, X.; Liao, Q.; Li, H.; Bai, S.; Wu, Y.; Lu, X.; Hu, H.; Shi, Q.; Fu, H. Near-infrared lasing from small-molecule organic hemispheres. J. Am. Chem. Soc. 2015, 137, 9289-9295.

[42] Lin, J.; Zhu, G.; Liu, B.; Yu, M.; Wang, X.; Wang, L.; Zhu, W.; Xie, L.; Xu, C.; Wang, J.; Stavrinou, P. N.; Bradley, D. D. C. Supramolecular polymer-molecule complexes as gain media for ultraviolet lasers. ACS Macro Lett. 2016, 5, 967-971.

[43] Lu, S.; Fang, H.; Feng, J.; Xia, H.; Zhang, T.; Chen, Q.; Sun, H. Highly stable on-chip embedded organic whispering gallery mode lasers. J. Lightwave. Technol. 2014, 32, 2415-2419.

[44] Yu, Z.; Wu, Y.; Zhang, H.; Wang, X.; Chen, J.; Yao, J.; Fu, H. Self-assembled 1D-nanowire lasers of perylenediimides. Chem. Phys. Chem. 2016, 17, 3160 - 3164.

[45] Zhou, X.; Liu, L.; Xu, T.; Liu, W.; Wang, R.; Yu, H.; Jiang, X.; Ma, Y. Low optical loss amplified spontaneous emission and lasing in a solution-processed organic semiconductor. Adv. Opt. Mater. 2019, 1900701.

[46] Liao, Q.; Wang, X.; Lv, S.; Xu, Z.; Zhang, Y.; Fu, H. Cluster-mediated nucleation and growth of J-and H-type polymorphs of difluoroboron avobenzone for organic microribbon lasers. ACS Nano 2018, 12, 5359-5367.

[47] Ou, C.; Ding, X.; Li, Y.; Zhu, C.; Yu, M.; Xie, L.; Lin, J.; Xu, C.; Huang, W. Conformational effect of polymorphic terfluorene on photophysics. crystal morphologies, and lasing behaviors. J. Phys. Chem. C 2017, 121, 14803-14810.

[48] Zhang, Z.; Wang, Z.; Xu, Z.; Gao, Q.; Liu, P.; Ren, J.; Li, M.; Zhou, C.; Liao, Q.; Fu, H. Soft lithography to fabricate 3D patterning organic microrings towards high - performance near infrared laser arrays. Adv. Opt. Mater. 2018, 6, 1800219.

[49] Takahashi1, W.; Maruyama1, K.; Li, J.; Imakawa, M.; Takenobu, T. Optical characteristic of 5,5-bis(4-biphenylyl)-2,2:5,2-terthiophene single-crystal thin-film resonator. Jpn. J. Appl. Phys. 2014, 53, 02BB02. 